\title{
Photochemistry of Long-Lived $\left[\left(\mathrm{CF}_{3}\right)_{2} \mathrm{CF}\right]_{2} \mathrm{C}^{\bullet} \mathrm{C}_{2} \mathrm{~F}_{5}$ Radicals
}

Sadulla R. Allayarov, ${ }^{1,2, *}$ Diliara A. Gordon ${ }^{2}$, Philip B. Henderson, ${ }^{3}$ Richard E. Fernandez, ${ }^{1}$ Virgil E. Jackson, ${ }^{1}$ and David A. Dixon ${ }^{1, *}$

${ }^{1}$ Department of Chemistry, The University of Alabama, Tuscaloosa, Alabama, USA, 354870336

E-mail: dadixon@bama.ua.edu

${ }^{2}$ Institute of Problems of Chemical Physics of the Russian Academy of Sciences, Chernogolovka, the Moscow Region, Russia, 142432

E-mail: $\underline{\text { sadush@icp.ac.ru }}$

${ }^{3}$ Air Products and Chemicals, Inc., 7201 Hamilton Blvd., Allentown, PA 18195-1501

\begin{abstract}
The mechanism of the photodecomposition of the long lived radical $\left[\left(\mathrm{CF}_{3}\right)_{2} \mathrm{CF}\right]_{2} \mathrm{C}^{\bullet} \mathrm{C}_{2} \mathrm{~F}_{5}$ is explored by UV and ESR spectroscopy and quantum chemical calculations. The kinetics of the photodecomposition of $\left[\left(\mathrm{CF}_{3}\right)_{2} \mathrm{CF}\right]_{2} \mathrm{C}^{\circ} \mathrm{C}_{2} \mathrm{~F}_{5}$ are investigated in a matrix of glassy and liquid hexafluoropropylene trimer at 77 and $300 \mathrm{~K}$, respectively. The mechanism of $\left[\left(\mathrm{CF}_{3}\right)_{2} \mathrm{CF}\right]_{2} \mathrm{C}^{\circ} \mathrm{C}_{2} \mathrm{~F}_{5}$ photodecomposition does not depend on the phase state of the matrix but differs from the thermal decomposition of the radical. Under UV light with $\lambda<300 \mathrm{~nm}$, the $\mathrm{CF}_{2}-\mathrm{CF}_{3}$ bond of the perfluoro-ethyl group of $\left[\left(\mathrm{CF}_{3}\right)_{2} \mathrm{CF}_{2} \mathrm{C}^{\bullet} \mathrm{C}_{2} \mathrm{~F}_{5}\right.$ is broken. Thermal decomposition of the radical above $373 \mathrm{~K}$ occurs by breaking a $\mathrm{CF}-\mathrm{CF}_{3}$ bond in the perfluoro-isopropyl group. The experimental results are consistent with the calculated bond dissociation energies and UV-vis excitation spectra of the radical. Additional calculated C-C BDEs for a number of fluorocarbon
\end{abstract}


radicals show that radicals can be designed with very low C-C BDEs for the generation of $\mathrm{CF}_{3}{ }^{\bullet}$ radicals.

Key words: long-lived perfluorocarbon radicals; thermal and photochemical decomposition; UV spectroscopy; ESR spectroscopy; bond dissociation energies; density functional theory. 


\section{Graphical Abstract}

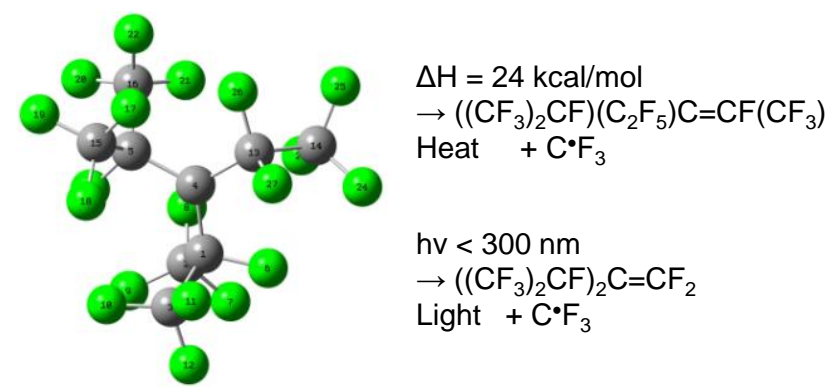

Synopsis: An experimental and computational study of the photodecomposition of the long lived radical $\left[\left(\mathrm{CF}_{3}\right)_{2} \mathrm{CF}\right]_{2} \mathrm{C}^{\bullet} \mathrm{C}_{2} \mathrm{~F}_{5}$ shows that the photodecomposition does not depend on the phase state of the matrix and proceeds by a different mechanism from that for thermal decomposition in terms of the initial bond that is cleaved.

\section{Highlights}

- Photochemical and thermal decomposition of $\left[\left(\mathrm{CF}_{3}\right)_{2} \mathrm{CF}_{2} \mathrm{C}^{\bullet} \mathrm{C}_{2} \mathrm{~F}_{5}\right.$ radicals yield different olefins

- Differences in decomposition pathways are consistent with calculated energies and excitations

- Perfluorocarbon radicals can be designed with very low C-C BDEs for $\mathrm{CF}_{3}{ }^{\bullet}$ generation

- The photodecomposition mechanism does not depend on the phase state of the matrix 


\section{Introduction}

Stable radicals are of broad interest, for example, as reactive acceptor or donor intermediates in organic chemistry or as paramagnetic probes and spin labels. They are effective inhibitors of polymerization processes as they frequently inhibit oxidation and are used as the working material in radio-frequency masers and magnetometers. Radicals can be stabilized in a variety of ways and a range of such species is known. [1] Fluorinated long-lived radicals (LLRs) in liquid perfluoro-organic compounds were first detected by Allayarov et al. [2] during the radiolysis of perfluoroorganic compounds, such as the hexafluoropropylene trimer $\left((\mathrm{HFP})_{3}\right)$ [2] and subsequently synthesized by Scherer and co-workers [3] by the fluorination of $(\mathrm{HFP})_{3}$. Allayarov [4] explored the formation of fluorinated LLRs by the $\gamma$-radiolysis of more than fifty fluoro-organic compounds and identified ten types of stable radicals in twenty fluoro-organic compounds. One of the most interesting radicals is the LLR $\left[\left(\mathrm{CF}_{3}\right)_{2} \mathrm{CF}\right]_{2} \mathrm{C}^{\bullet} \mathrm{C}_{2} \mathrm{~F}_{5}$ formed by the radiolysis of $(\mathrm{HFP})_{3}$.

The radical $\left[\left(\mathrm{CF}_{3}\right)_{2} \mathrm{CF}\right]_{2} \mathrm{C}^{\bullet} \mathrm{C}_{2} \mathrm{~F}_{5}$ is a colorless liquid [5] with a density $\mathrm{d}_{25}=2.05 \mathrm{~g} / \mathrm{cc}$. It is stable in ambient oxygen and slowly reacts with fluorine. When the $\left[\left(\mathrm{CF}_{3}\right)_{2} \mathrm{CF}\right]_{2} \mathrm{C}^{\bullet} \mathrm{C}_{2} \mathrm{~F}_{5}$ radical was sealed in Pyrex tubes with excess chlorine or bromine, no reaction was observed over a period of months at room temperature, suggesting that chlorine molecules and certainly bromine molecules are too large to get close enough to the radical center of $\left[\left(\mathrm{CF}_{3}\right)_{2} \mathrm{CF}\right]_{2} \mathrm{C}^{\bullet} \mathrm{C}_{2} \mathrm{~F}_{5}$ for the reaction to occur. Excess hydrogen bromide was condensed into a Pyrex tube containing $\left[\left(\mathrm{CF}_{3}\right)_{2} \mathrm{CF}\right]_{2} \mathrm{C}^{\bullet} \mathrm{C}_{2} \mathrm{~F}_{5}$ and also showed no reaction over months at room temperature. However, the radical is easily and quantitatively reduced by iodide ion. Treatment of a solution containing $\left[\left(\mathrm{CF}_{3}\right)_{2} \mathrm{CF}\right]_{2} \mathrm{C}^{\bullet} \mathrm{C}_{2} \mathrm{~F}_{5}$ (3.9 molar) with excess sodium iodide in acetone gives a rapid one electron transfer reaction yielding a mixture of isomers $\left[\left(\mathrm{CF}_{3}\right)_{2} \mathrm{CF}\right]_{2} \mathrm{C}=\mathrm{CFCF}_{3}$ and $\left(\mathrm{CF}_{3}\right)_{2} \mathrm{CF}$ - 
$\left(\mathrm{C}_{2} \mathrm{~F}_{5}\right) \mathrm{C}=\mathrm{C}\left(\mathrm{CF}_{3}\right)_{2}$ of $(\mathrm{HFP})_{3}$ in a ratio of $44: 1$ [6]. From the iodide ion experiment, one can deduce that the reduction potential of $\mathrm{R}_{\mathrm{F}}{ }^{\circ}$ radical is greater than $0.535 \mathrm{~V}$, the oxidation potential of iodide ion. Cyclic voltametry provides a more quantitative measurement, so a $10^{-3}$ molar $\left[\left(\mathrm{CF}_{3}\right)_{2} \mathrm{CF}\right]_{2} \mathrm{C}^{\bullet} \mathrm{C}_{2} \mathrm{~F}_{5}$ solution in acetonitrile containing tetraethylammonium tetrafluoroborate as the electrolyte was used. The cyclic voltammogram of $\left[\left(\mathrm{CF}_{3}\right)_{2} \mathrm{CF}_{2} \mathrm{C}^{\circ} \mathrm{C}_{2} \mathrm{~F}_{5}\right.$ indicated that a nonreversible reduction takes place in the range of 0.550 to $0.575 \mathrm{~V}$. This nonreversible behavior is expected as the anion can readily eliminate fluoride ion. The first ionization potential of $\left[\left(\mathrm{CF}_{3}\right)_{2} \mathrm{CF}\right]_{2} \mathrm{C}^{\bullet} \mathrm{C}_{2} \mathrm{~F}_{5}$ is $10.75 \mathrm{eV}$ showing that the unpaired electron of the $\left[\left(\mathrm{CF}_{3}\right)_{2} \mathrm{CF}\right]_{2} \mathrm{C}^{\bullet} \mathrm{C}_{2} \mathrm{~F}_{5}$ radical is tightly bound [7]. $\left[\left(\mathrm{CF}_{3}\right)_{2} \mathrm{CF}\right]_{2} \mathrm{C}^{\circ} \mathrm{C}_{2} \mathrm{~F}_{5}$ can undergo $\beta$-scission to yield an olefin and a new radical on heating above $353 \mathrm{~K}[5,7]$ or under UV irradiation. $[8,9,10]$ There have only been a few studies of the use of this radical for chemical applications. [11,12]

The current work explores features of the photodecomposition of $\left[\left(\mathrm{CF}_{3}\right)_{2} \mathrm{CF}\right]_{2} \mathrm{C}^{\circ} \mathrm{C}_{2} \mathrm{~F}_{5}$, formed by direct fluorination or by $\gamma$-irradiation of $(\mathrm{HFP})_{3}$.

\section{Results and discussion}

2.1 Structure of $\left[\left(\mathrm{CF}_{3}\right)_{2} \mathrm{CF}_{2} \mathrm{C}^{\circ} \mathrm{C}_{2} \mathrm{~F}_{5}\right.$ The structure of the radicals formed upon fluorination were explored by analyzing the doublet ESR spectrum with $\Delta \mathrm{H}=4.44 \mathrm{mT}$. The unpaired electron gives rise to a narrow line spectrum due to the interaction with one $\beta$ fluorine in the $\mathrm{C}_{2} \mathrm{~F}_{5}$ group [8]. The angular orientation of the $\beta$ fluorine can be determined from the ESR spectrum (Figure 1) using the equation $\alpha_{\mathrm{f}}(\beta)=\mathrm{Q}_{\beta} \rho \cos ^{2} \theta$, where $\alpha_{\mathrm{f}}(\beta)$ equals the $\beta$-fluorine hyperfine coupling, $\mathrm{Q}_{\beta}$ is a constant, $\rho$ is the spin density of the unpaired electron at the $\alpha$-carbon atom, and $\theta$ is the angle between a projection of the C-F bond and the axis of the orbital of the unpaired electron. For fluorine atom $\mathrm{F}(27)$ (see Figure 2), the hyperfine constant equals $4.44 \mathrm{mT}$ whereas $\mathrm{F}(26)$ on 
the $\mathrm{CF}_{2}$ of the perfluoroethyl fragment of the radical lies close to the nodal plane $\left(\theta=69.5^{\circ}\right)$ and is characterized by a small coupling. These measurements can be compared to previously published data on fluorocarbon radicals. [13]
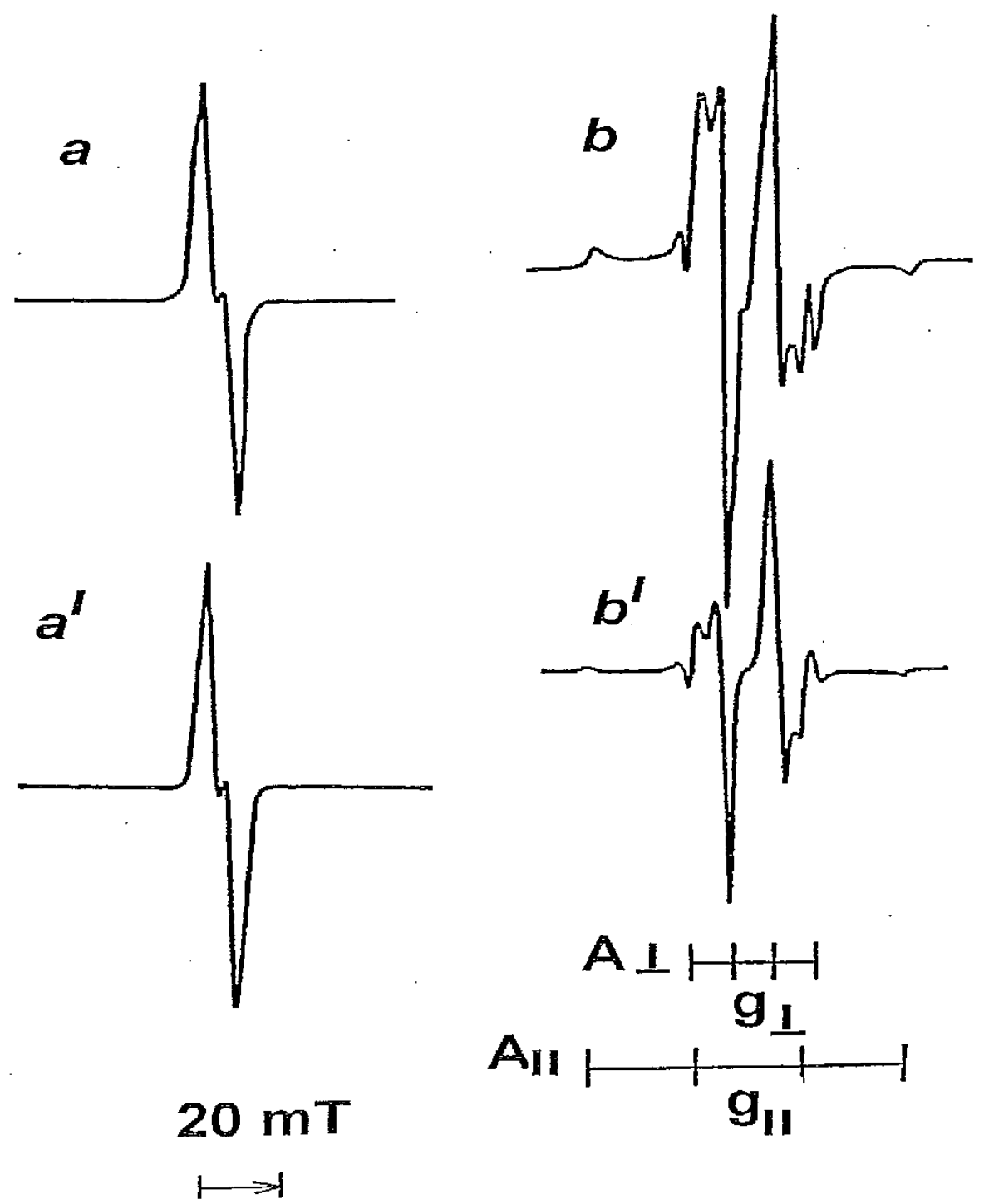

Figure 1. $(a, b)$ Experimental and $\left(a^{\prime}, b^{\prime}\right)$ simulated ESR spectra of the $\mathrm{R}_{\mathrm{F}}{ }^{\bullet}$ radicals in a glassy matrix of (HFP) $)_{3}$ observed (a, a') before and (b, b') after 800 min UV photolysis at $77 \mathrm{~K}$. The stick diagram for the ${ }^{\circ} \mathrm{CF}_{3}$ radical spectrum is shown below spectrum $b$ '. 


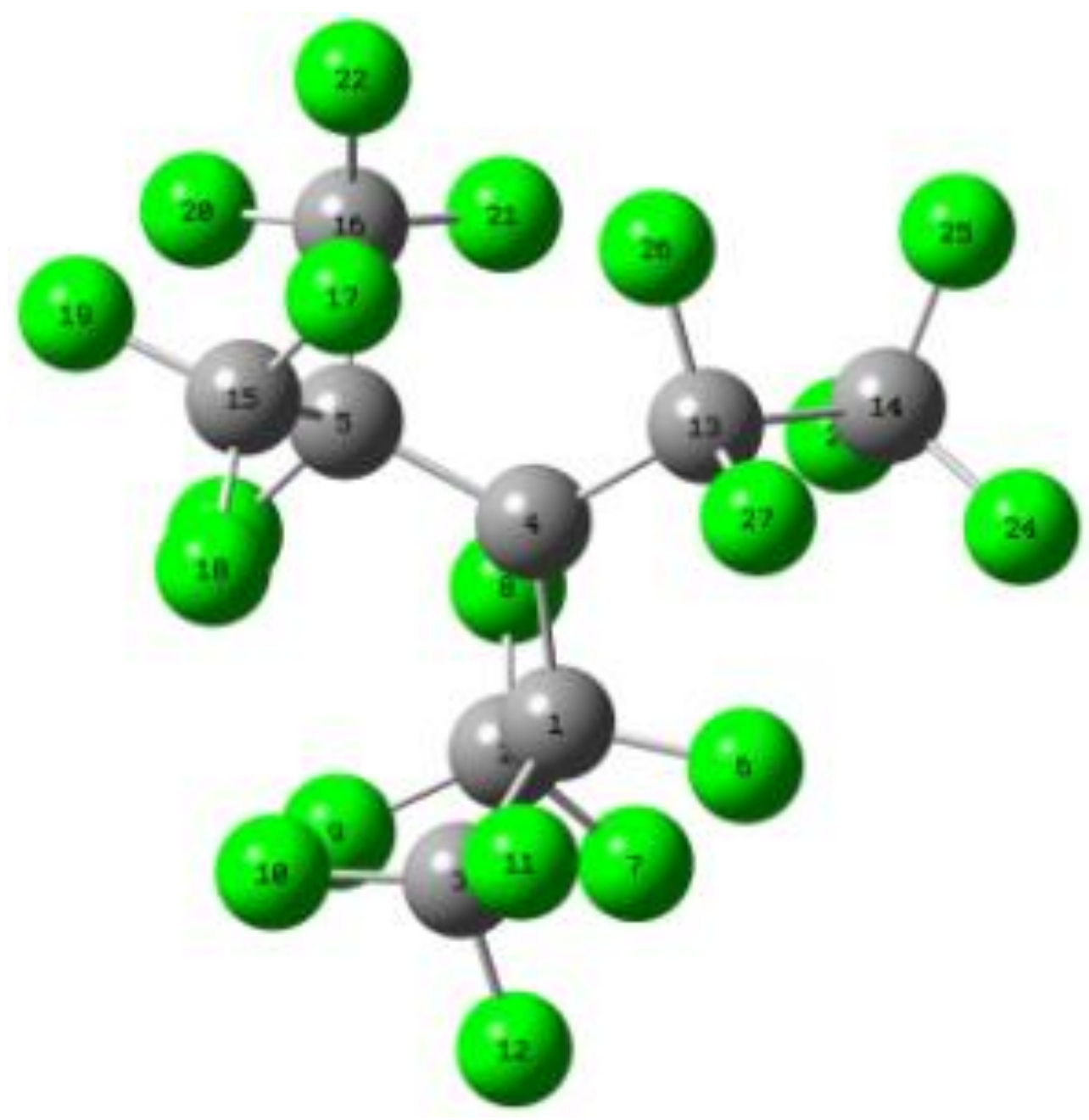

Figure 2. Optimized structure of $\mathrm{R}_{\mathrm{F}}{ }^{\circ}(\mathrm{I}),\left[\left(\mathrm{CF}_{3}\right)_{2} \mathrm{CF}\right]_{2} \mathrm{C}^{\bullet} \mathrm{C}_{2} \mathrm{~F}_{5}$, at the B3LYP/DZVP2 level.

The structure of $\left[\left(\mathrm{CF}_{3}\right)_{2} \mathrm{CF}\right]_{2} \mathrm{C}^{\circ} \mathrm{C}_{2} \mathrm{~F}_{5}$ was optimized using density functional theory (DFT) with the B3LYP functional and the DZVP2 basis set $[14,15,16]$ and is given in Figure 2; the orientations of the fluorine atoms are consistent with the ESR spectra. It has been established [8] that the structure of the radical in the liquid state does not differ from that found in the solid state, i.e. the conformation is apparently locked.

2.2 Mechanism of the photodecomposition of $\left[\left(\mathrm{CF}_{3}\right)_{2} \mathrm{CF}\right]_{2} \mathrm{C}^{\circ} \mathrm{C}_{2} \mathrm{~F}_{5}$ The ESR spectrum of the solid solution of $\left[\left(\mathrm{CF}_{3}\right)_{2} \mathrm{CF}\right]_{2} \mathrm{C}^{\circ} \mathrm{C}_{2} \mathrm{~F}_{5}$ in a glassy matrix of $(\mathrm{HFP})_{3}$ upon photolysis shows appreciable changes (Figure 1). The disappearance of the ESR spectrum of $\left[\left(\mathrm{CF}_{3}\right)_{2} \mathrm{CF}\right]_{2} \mathrm{C}^{\bullet} \mathrm{C}_{2} \mathrm{~F}_{5}$ (Figure 1a) is 
accompanied by the appearance of a complex ESR signal (Figure 1b) with a splitting of $75.5 \mathrm{mT}$ and four characteristic lines separated by $25.15 \mathrm{mT}$. In addition, the central part of the spectrum contains two asymmetric lines. The dependence of these lines with the time of UV irradiation and their appearance and disappearance as a function of heating was determined. All lines of the spectrum belong to ${ }^{\bullet} \mathrm{CF}_{3}$ radicals with axial symmetry and the three fluorine atoms of the radical are equivalent (Figure 1b). The principal components of the g-tensor and hyperfine couplings are: $\mathrm{A}_{\|}=25.15 \mathrm{mT}, \mathrm{A}_{\perp}=9.1 \mathrm{mT}$ and $\mathrm{g}_{\|}=1.9996, \mathrm{~g}_{\perp}=2.0056$ respectively. These spectra are representative of samples irradiated for a short time. Total decomposition of $\left[\left(\mathrm{CF}_{3}\right)_{2} \mathrm{CF}\right]_{2} \mathrm{C}^{\bullet} \mathrm{C}_{2} \mathrm{~F}_{5}$ in the solid phase happens only after UV-irradiation for a long time.

Photolysis of a solution of $\left[\left(\mathrm{CF}_{3}\right)_{2} \mathrm{CF}\right]_{2} \mathrm{C}^{\bullet} \mathrm{C}_{2} \mathrm{~F}_{5}$ radicals at $300 \mathrm{~K}$ generates new types of long-lived radicals (Figures 3a versus 3b). Upon UV irradiation, a new fluorocarbon radical $\mathrm{R}_{\mathrm{F}} \cdot(\mathrm{II})$, (Figure $3 \mathrm{~b}$ ) is formed and subsequently radical $\mathrm{R}_{\mathrm{F}}{ }^{\bullet}(\mathrm{III})$ is formed (Figure $3 \mathrm{c}$ ). The ESR spectrum for $\mathrm{RF}^{\bullet}(\mathrm{II})$ is due to $\left[\left(\mathrm{CF}_{3}\right)_{2} \mathrm{CF}\right]_{3} \mathrm{C}^{\bullet}$ formed by addition of ${ }^{\bullet} \mathrm{CF}_{3}$ to $\left[\left(\mathrm{CF}_{3}\right)_{2} \mathrm{CF}\right]_{2} \mathrm{C}=\mathrm{CFCF}_{3}$. Henderson [5] and Fernandez [7] have studied the addition of ${ }^{\bullet} \mathrm{CF}_{3}$ to $\left[\left(\mathrm{CF}_{3}\right)_{2} \mathrm{CF}\right]_{2} \mathrm{C}=\mathrm{CFCF}_{3}$ to give the triisopropyl radical and have observed the same ESR spectra growing in due to this addition. In the liquid state, about $90 \%$ of the $\mathrm{CF}_{3}{ }^{\bullet}$ radicals recombine with each other at $300 \mathrm{~K}$. Other radicals can also add to (HFP) $)_{3}$ leading to the formation of longlived radical $\mathrm{R}_{\mathrm{F}}^{\bullet}(\mathrm{II})$.

The ESR spectrum of $\mathrm{R}_{\mathrm{F}}{ }^{\circ}(\mathrm{III})$ (Figure $3 \mathrm{c}$ ) is observed after the disappearance of $\left[\left(\mathrm{CF}_{3}\right)_{2} \mathrm{CF}\right]_{2} \mathrm{C}^{\bullet} \mathrm{C}_{2} \mathrm{~F}_{5}$. We speculate on the structure of $\mathrm{R}_{\mathrm{F}} \cdot(\mathrm{III})$ from the ESR spectrum and the mechanism of its formation as follows. $\mathrm{R}_{\mathrm{F}}{ }^{\bullet}$ (III) could well be the isopropylethylmethyl radical, 

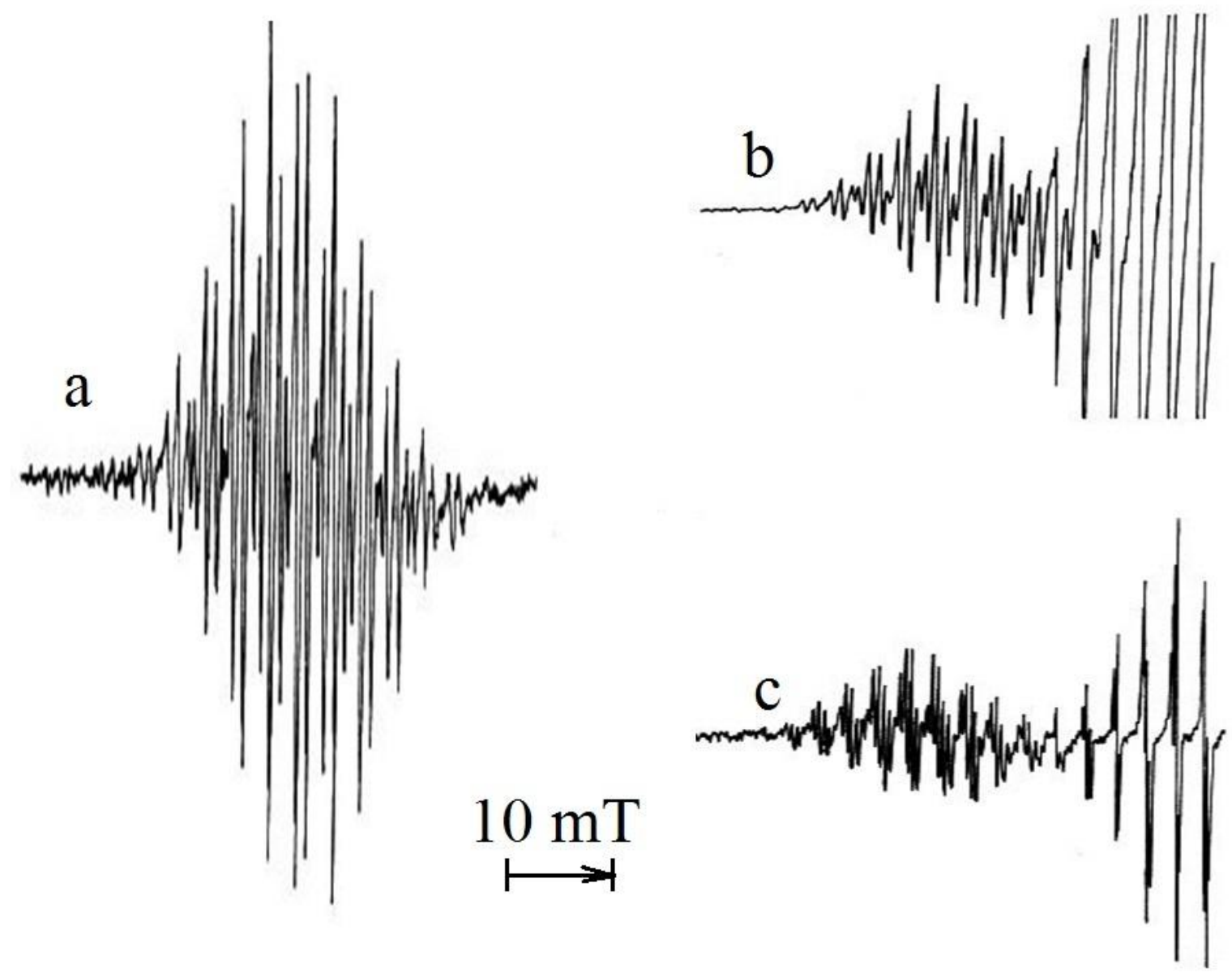

Figure 3. Left-hand portions of the ESR spectra of solutions of $\mathrm{R}_{\mathrm{F}}{ }^{\bullet}$ in $(\mathrm{HFP})_{3}$. (a) before photolysis, (b) after photolysis at $300 \mathrm{~K}$ for $200 \mathrm{~min}$, and (c) after photolysis at $300 \mathrm{~K}$ for 800 min. Initial concentrations of the radicals $R_{F}{ }^{\bullet}$ were $6 \times 10^{17} \mathrm{~g}^{-1}$ for (a) and (c) and $3 \times 10^{20} \mathrm{~g}^{-1}$ for (b).

$\left(\mathrm{CF}_{3}\right)_{2} \mathrm{CFC} \cdot\left(\mathrm{CF}_{3}\right) \mathrm{C}_{2} \mathrm{~F}_{5}$. Besides the residual olefin as a radical trap, $\mathrm{R}_{\mathrm{F}}{ }^{\circ}(\mathrm{I})$ can also serve as a trap as it is known to form the $\mathrm{C}_{10}$ alkane $\left[\left(\mathrm{CF}_{3}\right)_{2} \mathrm{CF}\right]_{2} \mathrm{CCF}_{3} \mathrm{C}_{2} \mathrm{~F}_{5}$ by the addition of $\mathrm{CF}_{3}$ to the radical carbon atom in $\mathrm{R}_{\mathrm{F}}{ }^{\circ}(\mathrm{I})$. [5,7] This $\mathrm{C}_{10}$ alkane is thermally labile to breaking a bond from the central carbon to one of the isopropyl carbons which yields $\left(\mathrm{CF}_{3}\right)_{2} \mathrm{CFC} \cdot\left(\mathrm{CF}_{3}\right) \mathrm{C}_{2} \mathrm{~F}_{5}$ and an isopropyl radical. The observed spectrum is consistent with the ESR spectra of the isopropylethylmethyl radical. [5] 
The decomposition rate of $\left[\left(\mathrm{CF}_{3}\right)_{2} \mathrm{CF}\right]_{2} \mathrm{C}^{\bullet} \mathrm{C}_{2} \mathrm{~F}_{5}$ as a function of $\mathrm{UV}$ wavelength is given in Figure 4 (curve 4 ). The radical begins to disappear at $\lambda<300 \mathrm{~nm}(\sim 4 \mathrm{eV})$. In order to better
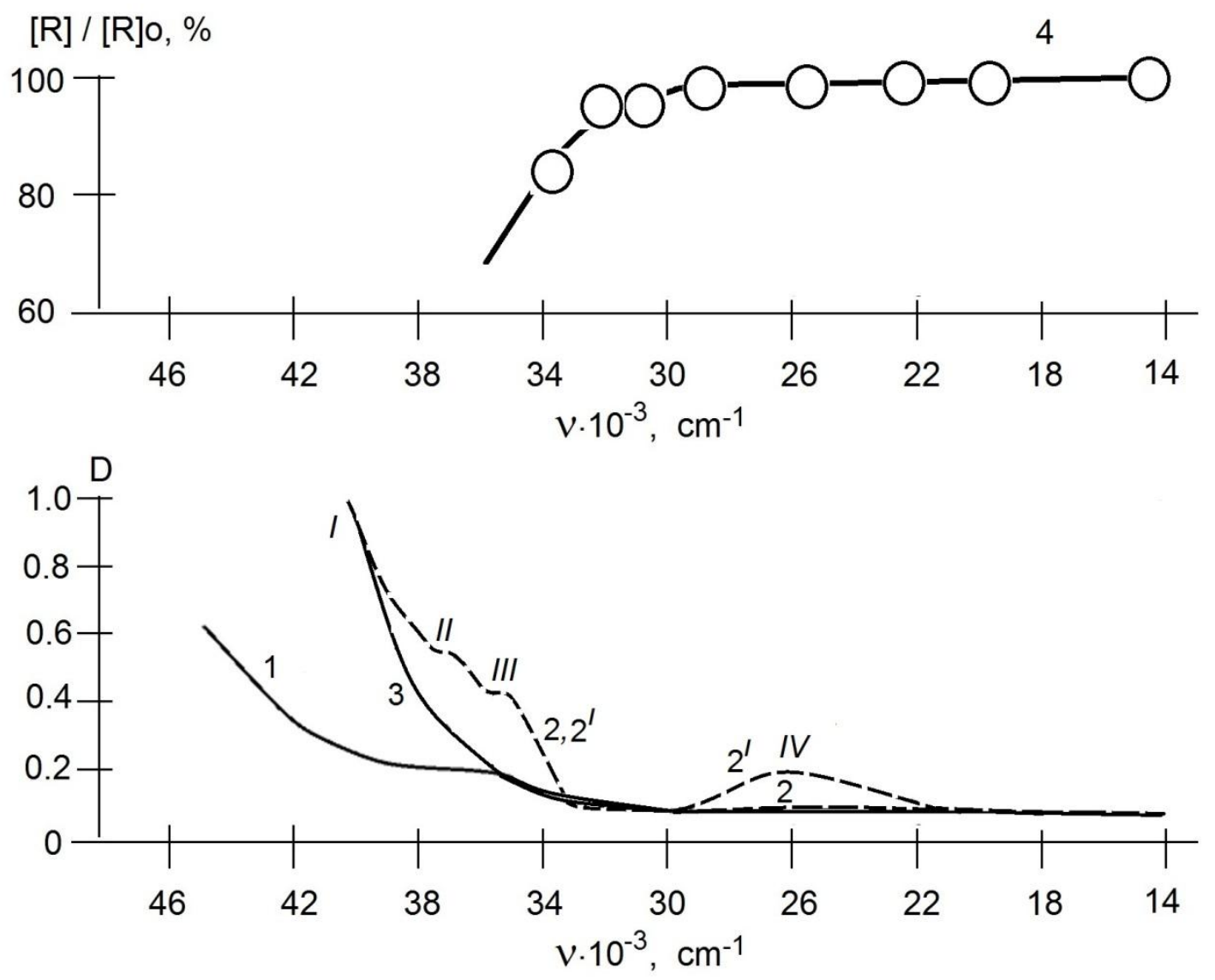

Figure 4. Absorption spectra at $300 \mathrm{~K}$ of irradiated $(\mathrm{HFP})_{3}$ products. Samples were irradiated at $300 \mathrm{~K} \mathrm{D}=110 \mathrm{kGy}$ being degassed (2') and in the presence of air (1, 2, 3): 1, 2, 2' - after irradiation, 3- after 3 month storage. 4 - kinetics of the radicals $\mathrm{RF}^{\bullet}$ decay versus wavelength of UV-light.

explain the dissociation processes, we predicted, using electronic structure methods, key bond dissociation energies (BDEs) that can lead directly to olefin formation without fluorine atom transfer (Table 1). DFT at the B3LYP/DZVP2 level underestimates the reaction energies so we used an isodesmic reaction approach to obtain improved BDEs by comparing reaction energies at the B3LYP/DZVP2 level with those at the composite correlated molecular orbital theory G4 
Table 1. Corrected B3LYP Reaction Energies in kcal/mol for Perfluorocarbon Chains. ${ }^{\text {a }}$

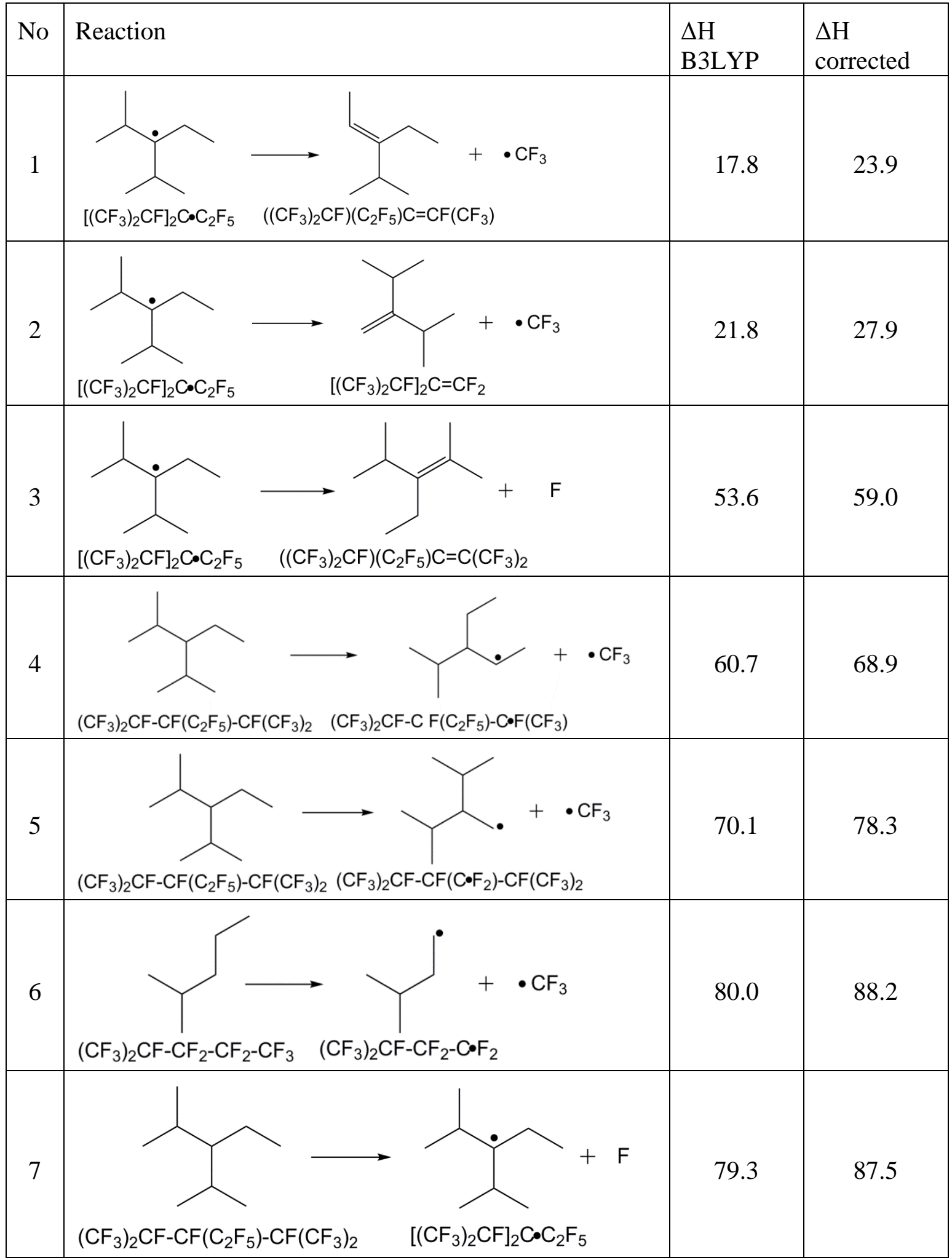




\begin{tabular}{|c|c|c|c|}
\hline 8 & {$\left[\left(\mathrm{CF}_{3}\right)_{2} \mathrm{CF}\right]_{2} \mathrm{C}=\mathrm{CFCF}_{3}$} & 7.5 & 13.6 \\
\hline 9 & $\left(\mathrm{CF}_{3}\right)_{2} \mathrm{CF}-\mathrm{C} \cdot\left(\mathrm{C}_{2} \mathrm{~F}_{5}\right)-\mathrm{C}\left(\mathrm{CF}_{3}\right)_{3} \quad\left(\mathrm{CF}_{3}\right)_{2} \mathrm{CF}-\mathrm{C}\left(\mathrm{C}_{2} \mathrm{~F}_{5}\right)=\mathrm{C}\left(\mathrm{CF}_{3}\right)_{2}$ & 3.7 & 9.8 \\
\hline 10 & $\left(\mathrm{CF}_{3}\right)_{2} \mathrm{CF}-\mathrm{C}\left(\mathrm{CF}_{3}\right)\left(\mathrm{C}_{2} \mathrm{~F}_{5}\right)-\mathrm{C} \cdot\left(\mathrm{CF}_{3}\right)_{2} \quad\left(\mathrm{CF}_{3}\right)_{2} \mathrm{CF}-\mathrm{C}\left(\mathrm{C}_{2} \mathrm{~F}_{5}\right)=\mathrm{C}\left(\mathrm{CF}_{3}\right)_{2}$ & 1.4 & 7.5 \\
\hline 11 & $\left.\mathrm{CF}_{3}\right)_{2} \mathrm{CF}-\mathrm{C} \cdot \mathrm{F}-\mathrm{CF}_{2}-\mathrm{CF}_{3} \quad \mathrm{CF}_{3} \mathrm{CF}=\mathrm{CF}-\mathrm{CF}_{2}-\mathrm{CF}_{3}$ & 22.1 & 28.2 \\
\hline 12 & $\left.\right|_{\left.\left(\mathrm{CF}_{3}\right)_{2} \mathrm{CF}-\mathrm{C} \cdot \mathrm{F}-\mathrm{CF}_{2}-\mathrm{CF}_{3} \quad \mathrm{CF}_{3}\right)_{2} \mathrm{CF}-\mathrm{CF}=\mathrm{CF}_{2}} ^{+}+\mathrm{CF}_{3}$ & 30.5 & 36.6 \\
\hline 13 & 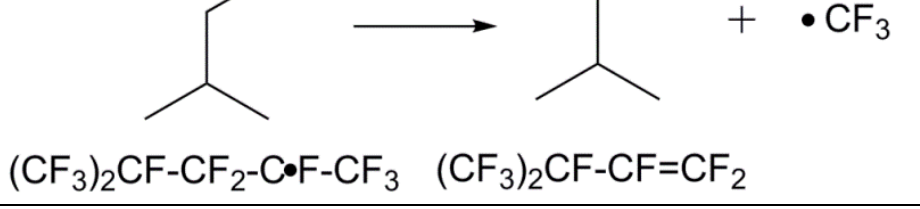 & 27.5 & 33.6 \\
\hline 14 & {$\left[\left(\mathrm{CF}_{3}\right)_{2} \mathrm{CF}-\mathrm{C} \cdot \mathrm{F}-\mathrm{CF}\left(\mathrm{CF}_{3}\right)_{2} \quad\left[\left(\mathrm{CF}_{3}\right)_{2} \mathrm{CF}-\mathrm{CF}=\mathrm{CF}-\mathrm{CF}_{3}\right.\right.$} & 26.8 & 32.9 \\
\hline
\end{tabular}




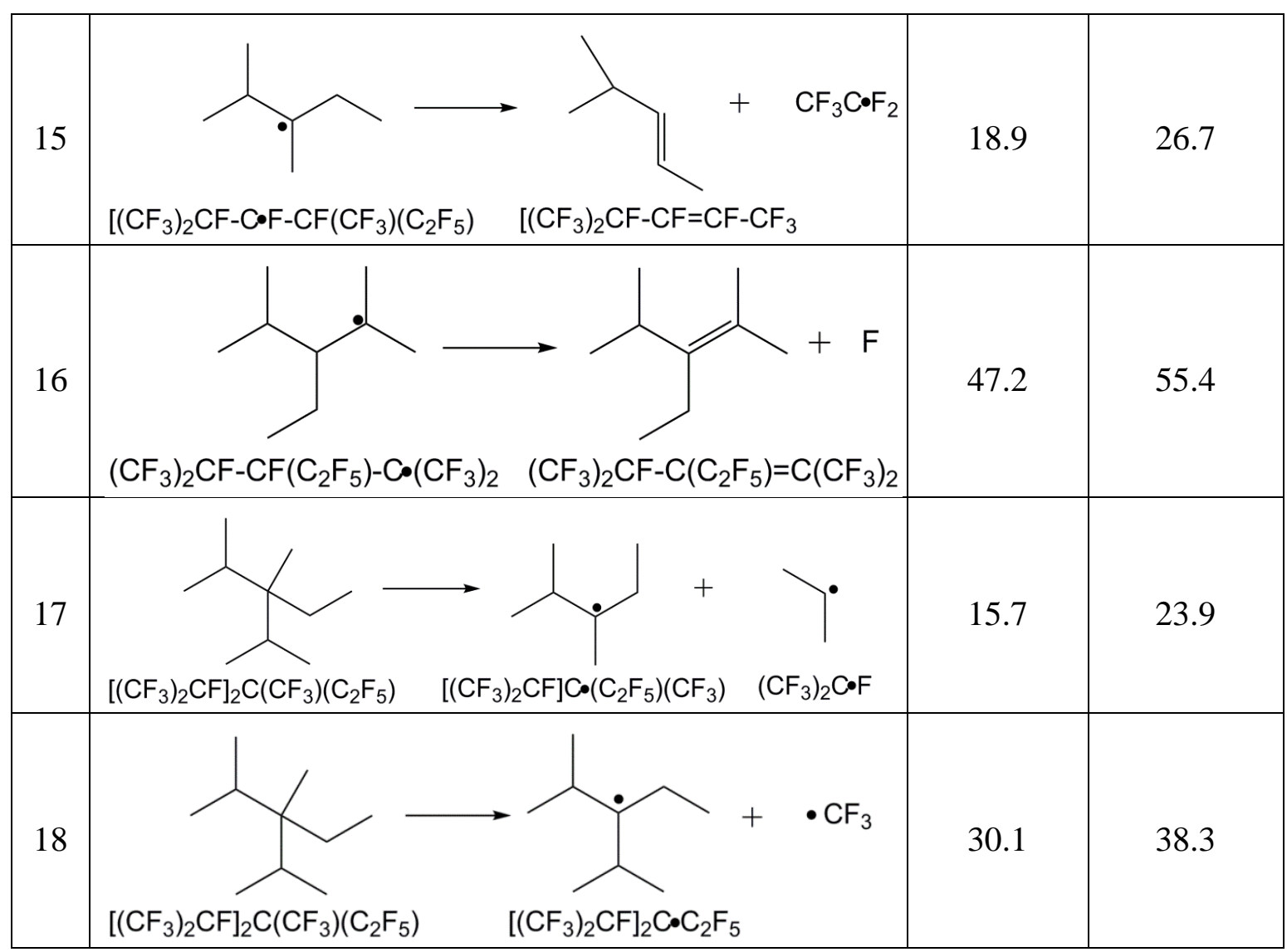

${ }^{a}$ All missing bonds are to $\mathrm{F}$. Only the $\mathrm{C}$ framework is shown.

level, [17] which we have previously shown to be in good agreement with the best available data. [18] The corrections from the following reactions were used: $\mathrm{C}_{2} \mathrm{~F}_{4}+\mathrm{CF}_{3}^{\bullet} \rightarrow \mathrm{CF}_{3} \mathrm{CF}_{2} \mathrm{CF}_{2}^{\bullet}(6.1$ $\mathrm{kcal} / \mathrm{mol})$ for reactions $(1,2,8-14) ; \mathrm{C}_{2} \mathrm{~F}_{4}+\mathrm{F}^{\bullet} \rightarrow \mathrm{CF}_{3} \mathrm{CF}_{2}^{\bullet}(5.4 \mathrm{kcal} / \mathrm{mol})$ for reaction (3); $\mathrm{C}_{2} \mathrm{~F}_{5}{ }^{\bullet}$ $+\mathrm{CF}_{3}^{\bullet} \rightarrow \mathrm{C}_{3} \mathrm{~F}_{8}(8.2 \mathrm{kcal} / \mathrm{mol})$ for reactions $(4-6,17,18) ; \mathrm{C}_{2} \mathrm{~F}_{5}^{\bullet}+\mathrm{F}^{\bullet} \rightarrow \mathrm{C}_{2} \mathrm{~F}_{6}(8.2 \mathrm{kcal} / \mathrm{mol})$ for reactions (7, 16); and $\mathrm{C}_{2} \mathrm{~F}_{4}+\mathrm{C}_{2} \mathrm{~F}_{5} \bullet \rightarrow \mathrm{CF}_{3} \mathrm{CF}_{2} \mathrm{CF}_{2} \mathrm{CF}_{2}^{\bullet}(7.8 \mathrm{kcal} / \mathrm{mol})$ for reaction (15). [18]

The C-C BDE for losing a $\mathrm{CF}_{3}^{\bullet}$ group is $4 \mathrm{kcal} / \mathrm{mol}$ stronger in the perfluoroethyl group than in the perfluoroisopropyl group (Reactions (1) and (2)). The stronger C-C BDE is 28 $\mathrm{kcal} / \mathrm{mol}$, much less than the loss of $\mathrm{F}^{\bullet}$ from the perfluoroisopropyl group with a C-F BDE of 59 $\mathrm{kcal} / \mathrm{mol}$ (reaction (3)). We note that these BDEs are much less than the C-C BDE of $96 \mathrm{kcal} / \mathrm{mol}$ and the $\mathrm{C}-\mathrm{F}$ BDE of $124 \mathrm{kcal} / \mathrm{mol}$ in $\mathrm{C}_{2} \mathrm{~F}_{6}$ at the $\mathrm{G} 4$ level. These results show that, for thermal 
decomposition, the $\mathrm{C}-\mathrm{C}$ bond in the isopropyl group should be the first to break. We further predicted the $\mathrm{C}-\mathrm{C}$ BDEs in a number of other branched perfluoroalkane chains and all have $\mathrm{C}-\mathrm{C}$ BDEs for loss of a $\mathrm{CF}_{3}{ }^{\bullet}$ group in the range of $70-90 \mathrm{kcal} / \mathrm{mol}$. The C-F BDE for the formation of $\left[\left(\mathrm{CF}_{3}\right)_{2} \mathrm{CF}\right]_{2} \mathrm{C}^{\bullet} \mathrm{C}_{2} \mathrm{~F}_{5}$ from $\left[\left(\mathrm{CF}_{3}\right)_{2} \mathrm{CF}_{2} \mathrm{CFC}_{2} \mathrm{~F}_{5}\right.$ is only $88 \mathrm{kcal} / \mathrm{mol}$, much lower than a usual $\mathrm{C}-\mathrm{F}$ BDE further demonstrating the stability of the $\left[\left(\mathrm{CF}_{3}\right)_{2} \mathrm{CF}_{2} \mathrm{C}^{\circ} \mathrm{C}_{2} \mathrm{~F}_{5}\right.$ radical. The negative of reaction (18) represents the capture of a $\mathrm{CF}_{3}{ }^{\bullet}$ by $\mathrm{R}_{\mathrm{f}}(\mathrm{I})$ to generate the $\mathrm{C}_{10}$ alkane. It is substantially exothermic consistent with the observation that $\mathrm{R}_{\mathrm{f}}(\mathrm{I})$ can trap $\mathrm{CF}_{3}{ }^{\circ}$. Reaction (17) represents the loss of an isopropyl group from the $\mathrm{C}_{10}$ alkane and the low $\mathrm{C}-\mathrm{C} \mathrm{BDE}$ is consistent with the formation of $\mathrm{R}_{\mathrm{f}}(\mathrm{III})$ from the $\mathrm{C}_{10}$ perfluoroalkane.

In order to further explore the properties of $\left[\left(\mathrm{CF}_{3}\right)_{2} \mathrm{CF}_{2} \mathrm{C}^{\circ} \mathrm{C}_{2} \mathrm{~F}_{5}\right.$, we used time-dependent density functional theory (TD-DFT) to predict the excitation spectra for the doublet states. The important orbitals are shown in Figure 5. The first transition was predicted to be at $269.8 \mathrm{~nm}$ ( $\mathrm{f}=$ 0.002) and is from the highest doubly occupied molecular orbital (DOMO1) to the singly occupied orbital (SOMO). The SOMO is a p orbital on the radical carbon and DOMO1 is an orbital involving the $\mathrm{C}-\mathrm{C}$ bond between the $\mathrm{CF}_{2}$ on the $\mathrm{CF}_{2} \mathrm{CF}_{3}$ group and the $\mathrm{CF}_{3}$ as well as between the $\mathrm{CF}_{2}$ and the radical $\mathrm{C}$ center. The second excitation is predicted to be more intense at $248.0 \mathrm{~nm}(\mathrm{f}=0.031)$ and is from DOMO2 to the SOMO. DOMO2 involves $\mathrm{CF}_{-} \mathrm{CF}_{3}$ bonds in the isopropyl groups. The next excitation is at $242.3 \mathrm{~nm}(\mathrm{f}=0.001)$ and is from DOMO4 to the SOMO. DOMO4 involves the $\mathrm{C}-\mathrm{C}$ bonds between the radical $\mathrm{C}$ and the central $\mathrm{C}(\mathrm{F})$ in the isopropyl groups. The next excitation is at $238.2 \mathrm{~nm}(\mathrm{f}=0.0111)$ and is from DOMO3 to the SOMO which is like the DOMO2 to SOMO transition.

The decomposition of $\mathrm{R}_{\mathrm{F}}{ }^{\circ}$ occurs for $\lambda<300 \mathrm{~nm}$, consistent with the calculated values. Upon photolysis of $\left[\left(\mathrm{CF}_{3}\right)_{2} \mathrm{CF}\right]_{2} \mathrm{C}^{\circ} \mathrm{C}_{2} \mathrm{~F}_{5}$, the $\mathrm{CF}_{2}-\mathrm{CF}_{3}$ bond in the perfluoroethyl group is broken, 
consistent with the TD-DFT calculations. Upon thermal decomposition, the $\mathrm{CF}-\mathrm{CF}_{3}$ bond in the isopropyl group is broken so the photodecomposition (reaction (2)) and thermal decomposition (reaction (1)) reactions generate different olefins. The thermal decomposition results are consistent with the DFT calculations, and the C-C BDE for reaction (1) is less than that for reaction (2).

2.3 Kinetics of photodecomposition of LLRs in the glassy and liquid matrices of $(\mathrm{HFP})_{3}$ at 77 and $300 \mathrm{~K}$, respectively, The dependence of concentration of $\left[\left(\mathrm{CF}_{3}\right)_{2} \mathrm{CF}\right]_{2} \mathrm{C}^{\bullet} \mathrm{C}_{2} \mathrm{~F}_{5}$ on the photolysis time in a liquid matrix of $(\mathrm{HFP})_{3}$ is given in Figure 6. Photolysis of samples containing $\left[\left[\left(\mathrm{CF}_{3}\right)_{2} \mathrm{CF}\right]_{2} \mathrm{C}^{\bullet} \mathrm{C}_{2} \mathrm{~F}_{5}\right]=6 \times 10^{17}$ to $6 \times 10^{18} \mathrm{~g}^{-1}$ exhibited similar decomposition kinetics (curves $\mathrm{C}$ to $\mathrm{E}$ ). The destruction of radicals during photolysis of a solution containing $\left[\left[\left(\mathrm{CF}_{3}\right)_{2} \mathrm{CF}\right]_{2} \mathrm{C}^{\bullet} \mathrm{C}_{2} \mathrm{~F}_{5}\right]=3 \times 10^{20} \mathrm{~g}^{-1}$ had the lowest rate (curve $\mathrm{B}$ ) with the same intensity of light.

The kinetics of the solid phase photo decomposition of $\left[\left(\mathrm{CF}_{3}\right)_{2} \mathrm{CF}\right]_{2} \mathrm{C}^{\bullet} \mathrm{C}_{2} \mathrm{~F}_{5}$ in the glassy matrix of $(\mathrm{HFP})_{3}$ at $77 \mathrm{~K}$ is shown in Figure 7. It is apparent the photodecomposition kinetics in samples containing $\left[\left[\left(\mathrm{CF}_{3}\right)_{2} \mathrm{CF}\right]_{2} \mathrm{C}^{\bullet} \mathrm{C}_{2} \mathrm{~F}_{5}\right]=3 \times 10^{20} \mathrm{~g}^{-1}$ (curve $\mathrm{B}$ ) differs from that for $\left[\left[\left(\mathrm{CF}_{3}\right)_{2} \mathrm{CF}\right]_{2} \mathrm{C}^{\bullet} \mathrm{C}_{2} \mathrm{~F}_{5}\right]=6 \times 10^{17} \mathrm{~g}^{-1}$ (curve $\mathrm{C}$ ) as the higher concentration again exhibits slower rates. It is not yet possible to determine if the difference of the kinetics in the liquid and solid states is just a temperature effect.

2.4 Optical properties of $\gamma$-irradiated liquid $(H F P)_{3}$ The optical absorption of liquid (HFP) 3 consists of two absorption peaks: (I) with $\lambda_{\max } \leq 185 \mathrm{~nm}$ and (II) with $\lambda \approx 250 \mathrm{~nm}\left(\mathrm{e}_{250}=61\right.$ mole $\mathrm{cm}^{-1}$ ) (Figure 8, curve 1). In this sample, Peak I can only be observed using a very thin cuvette with a thickness of $10^{-4} \mathrm{~cm}$ (Figure 8, curve 2) as this peak was not observed on samples with thicker cuvettes. 


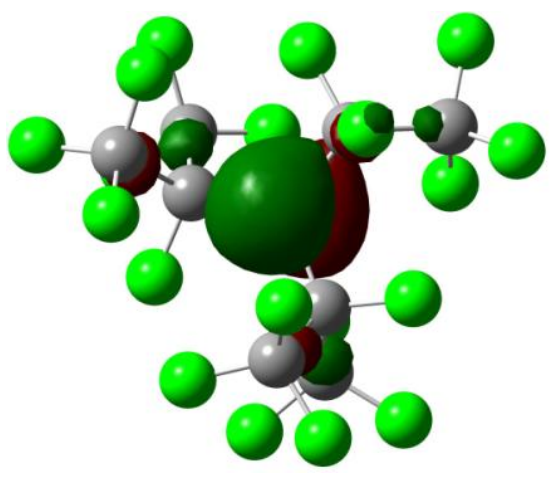

SOMO

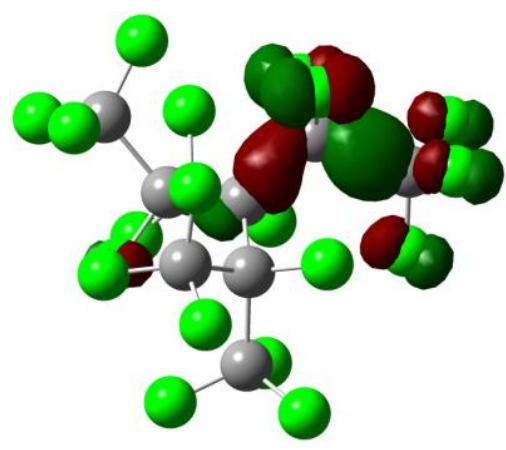

DOMO1

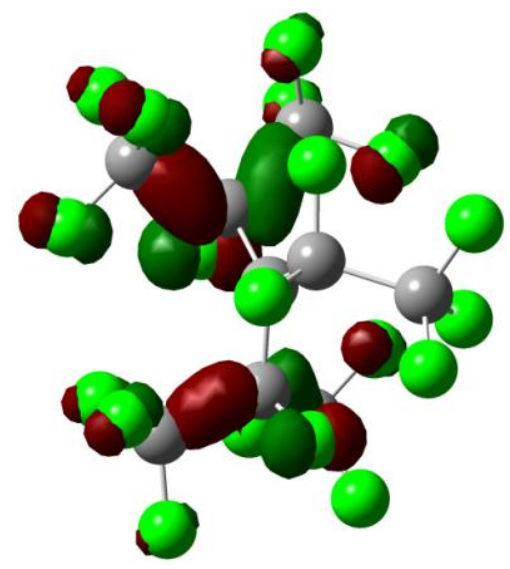

DOMO3

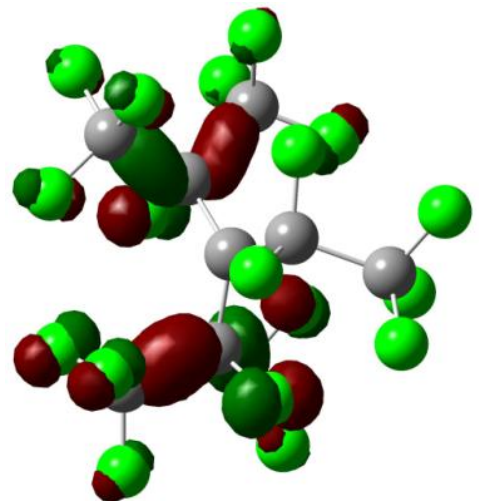

DOMO2

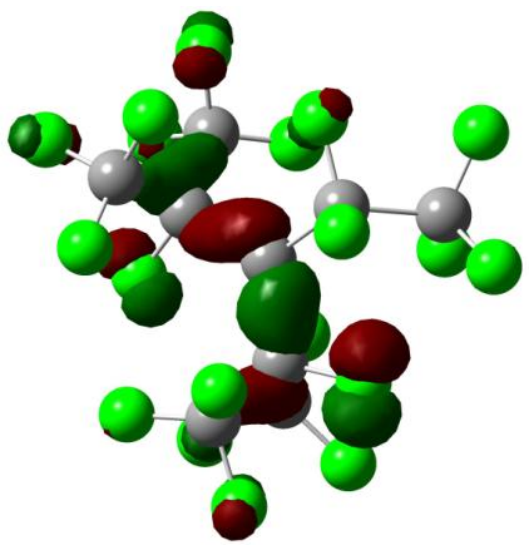

$\mathrm{DOMO} 4$

Figure 5. High lying molecular orbitals of $\left[\left(\mathrm{CF}_{3}\right)_{2} \mathrm{CF}\right]_{2} \mathrm{C}^{\circ} \mathrm{C}_{2} \mathrm{~F}_{5}$. 


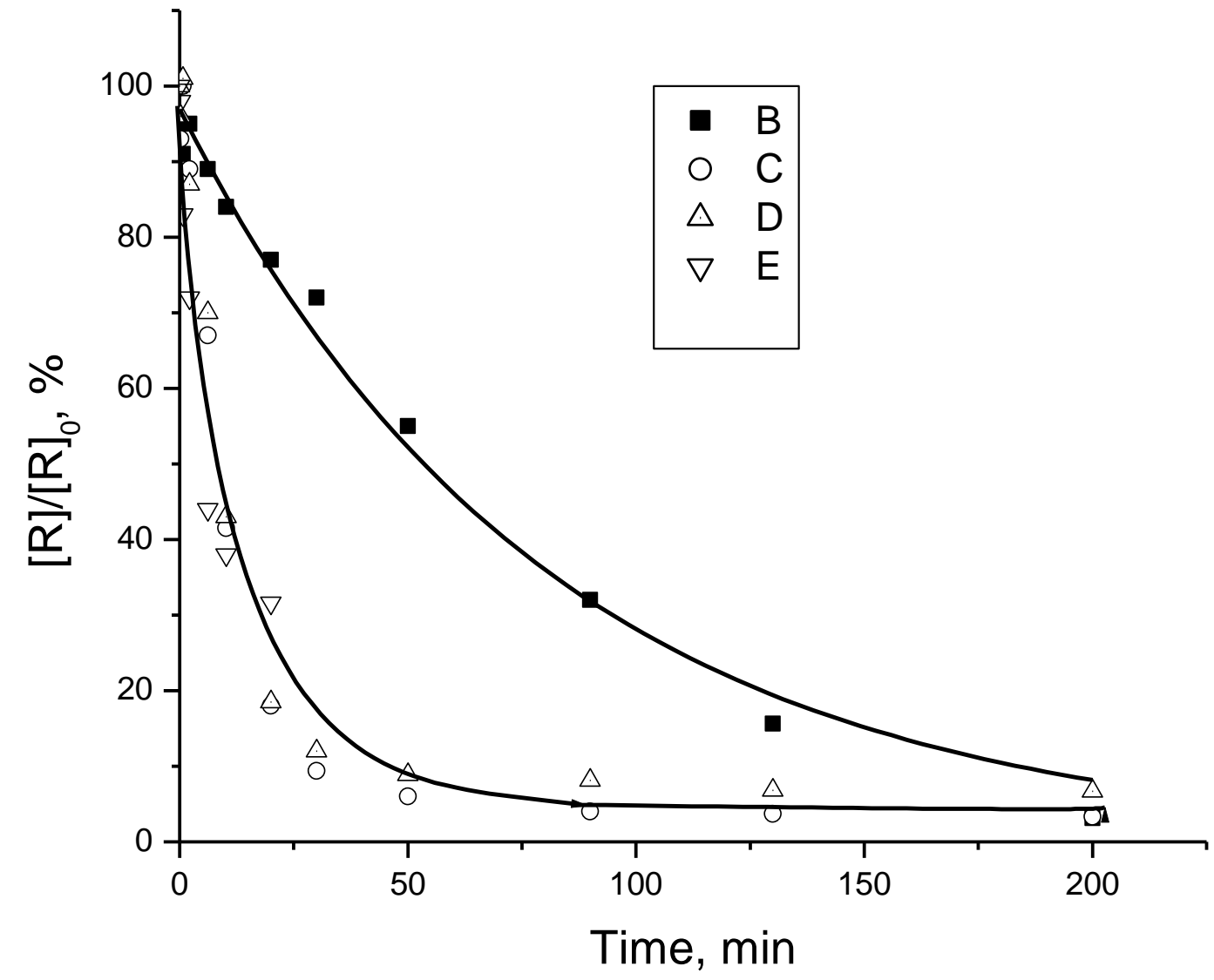

Figure 6. Concentration of radicals in liquid phase versus UV irradiation time at $300 \mathrm{~K}$, containing $3 \times 10^{20}(\mathrm{~B}), 6 \times 10^{18}(\mathrm{C}), 3 \times 10^{18}(\mathrm{D})$ and $6 \times 10^{17} \mathrm{~g}^{-1}(\mathrm{E})$ of $\mathrm{R}_{\mathrm{F}}{ }^{\bullet}$ in the liquid $(\mathrm{HFP})_{3}$. The curve through the set of points $\mathrm{B}$ is a second-order polynomial regression trend line generated by Excel. The cure through the set of points $\mathrm{C}, \mathrm{D}, \mathrm{E}$ is a fifth-order polynomial regression trend line. The curves are drawn to show how the points correlate.

Four peaks at $\lambda_{\max }<240 \mathrm{~nm}(\mathrm{I}), \approx 270 \mathrm{~nm}(\mathrm{II})$, and $\approx 285 \mathrm{~nm}$ (III), and $\approx 400 \mathrm{~nm}$ (IV) are observed in the optical spectra of the $(\mathrm{HFP})_{3}$ irradiated by $\gamma$-rays in vacuum at $300 \mathrm{~K}$ (Figure 4, curve 2'; dashed line). The intensity of all four peaks decreased upon UV irradiation. However, the peaks change in different ways and the changes depend on experimental conditions. Peak IV does not appear in the samples irradiated with $\gamma$-rays in air (curve 2, Figure 4), whereas the presence of the other three peaks (curves 2 and 2') does not depend on the presence of air during the radiolysis. All peaks disappear within one month (curve 3) except for 
peak I. These results suggest that there may be three types of photosensitive centers in the $\gamma$ irradiated $(\mathrm{HFP})_{3}$.

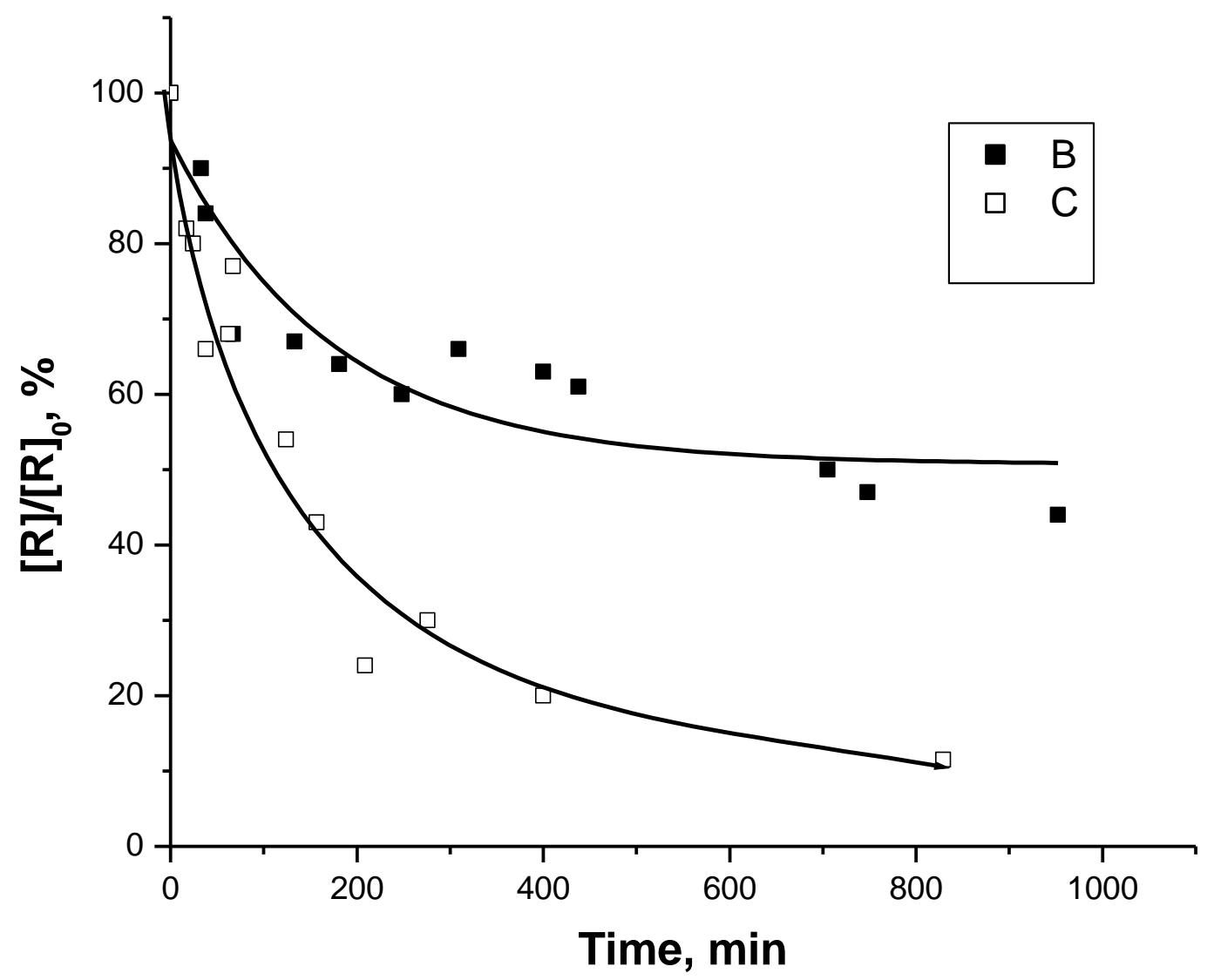

Figure 7. Concentration of radicals $\mathrm{R}_{\mathrm{F}}{ }^{\bullet}$ in a glassy matrix versus UV irradiation time at $77 \mathrm{~K}$, containing $3 \times 10^{20}$ (B) and $6 \times 10^{17} \mathrm{~g}^{-1}(\mathrm{C})$ of $\mathrm{R}_{\mathrm{F}}{ }^{\bullet}$. The curve through the set of points $\mathrm{B}$ is a fifthorder polynomial regression trend line generated by Excel. The cure through the set of points $\mathrm{C}$ is a third-order polynomial regression trend line. The curves are drawn to show how the points correlate.

The first type of photosensitive center is characterized by the peak absorption (I), which does not change with time of the storage of the $\gamma$-irradiated $(\mathrm{HFP})_{3}$ and is not sensitive to the presence of air. Peaks (II) and (III), which disappear upon storage and are not sensitive to the presence of oxygen, correspond to the second type of photosensitive center. Peak IV is due to the 
third type of the photosensitive center. Peak IV is not formed upon radiolysis of $(\mathrm{HFP})_{3}$ in the presence of air. After storage of the $\gamma$-irradiated $(\mathrm{HFP})_{3}$ for three months, the optical spectrum showed peak (I) (Fig. 4, curve 3) and a doublet ESR spectrum with $\Delta \mathrm{H}=3.9 \mathrm{mT}$.

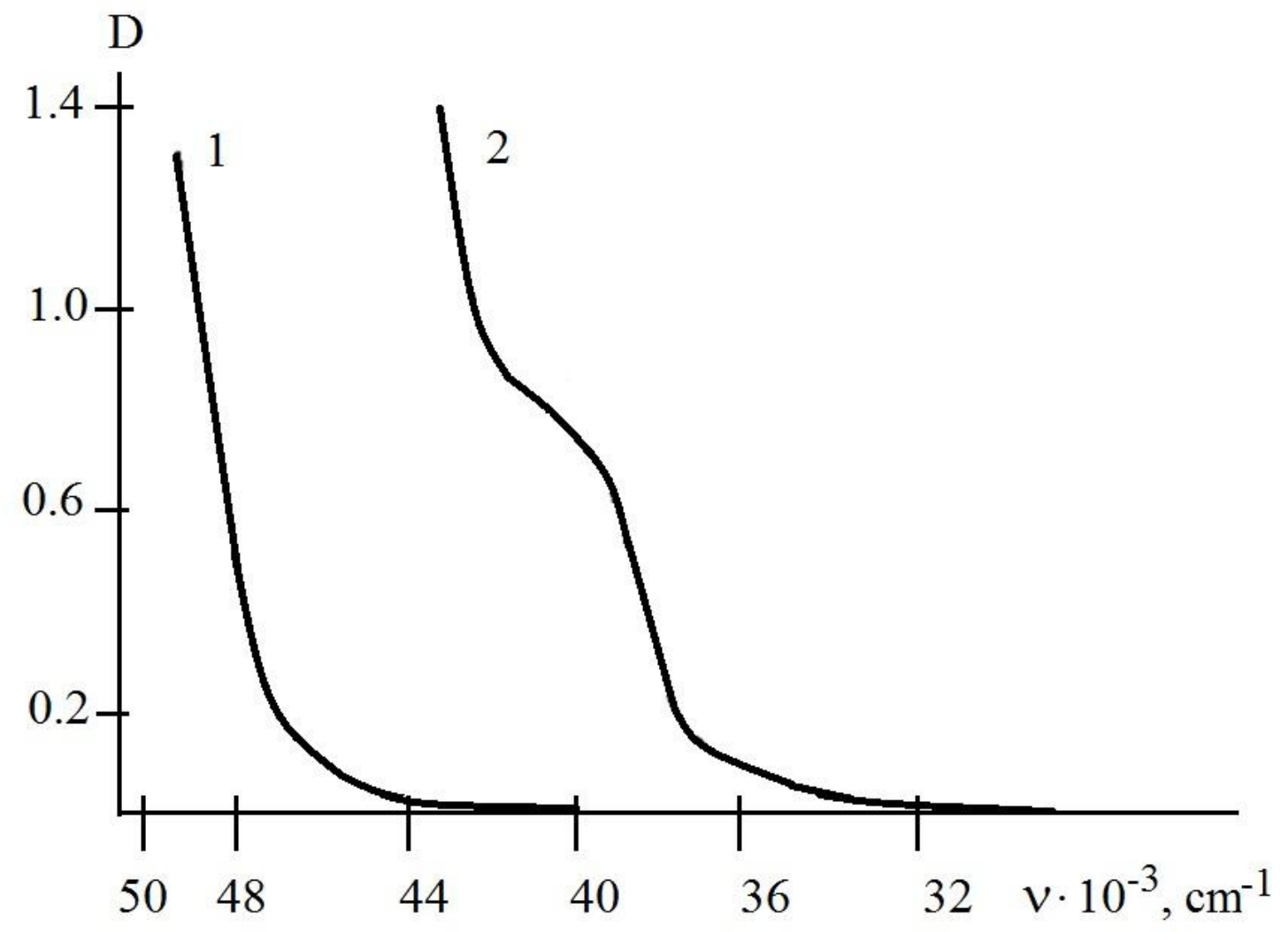

Figure 8. Absorption spectra at 300K: 1 - $(\mathrm{HFP})_{3}\left(\right.$ liquid, $\left.\mathrm{l}=10^{-4} \mathrm{~cm}\right) ; 2-(\mathrm{HFP})_{3}\left(\mathrm{l}=10^{-1} \mathrm{~cm}\right)$

The decay processes of $\left[\left(\mathrm{CF}_{3}\right)_{2} \mathrm{CF}_{2} \mathrm{C}^{\bullet} \mathrm{C}_{2} \mathrm{~F}_{5}\right.$ under UV light were explored by observing the changes in absorption peak I (curve C, Figure 9) and by ESR (curves B, D, Figure 9). The decay rate of $\left[\left(\mathrm{CF}_{3}\right)_{2} \mathrm{CF}\right]_{2} \mathrm{C}^{\bullet} \mathrm{C}_{2} \mathrm{~F}_{5}$ formed upon both fluorination and radiolysis of $(\mathrm{HFP})_{3}$ coincides with the rate of decrease of the absorption peak (I). This supports the assignment of absorption peak (I) with $\lambda<220 \mathrm{~nm}$ to $\left[\left(\mathrm{CF}_{3}\right)_{2} \mathrm{CF}_{2} \mathrm{C}^{\circ} \mathrm{C}_{2} \mathrm{~F}_{5}\right.$. 


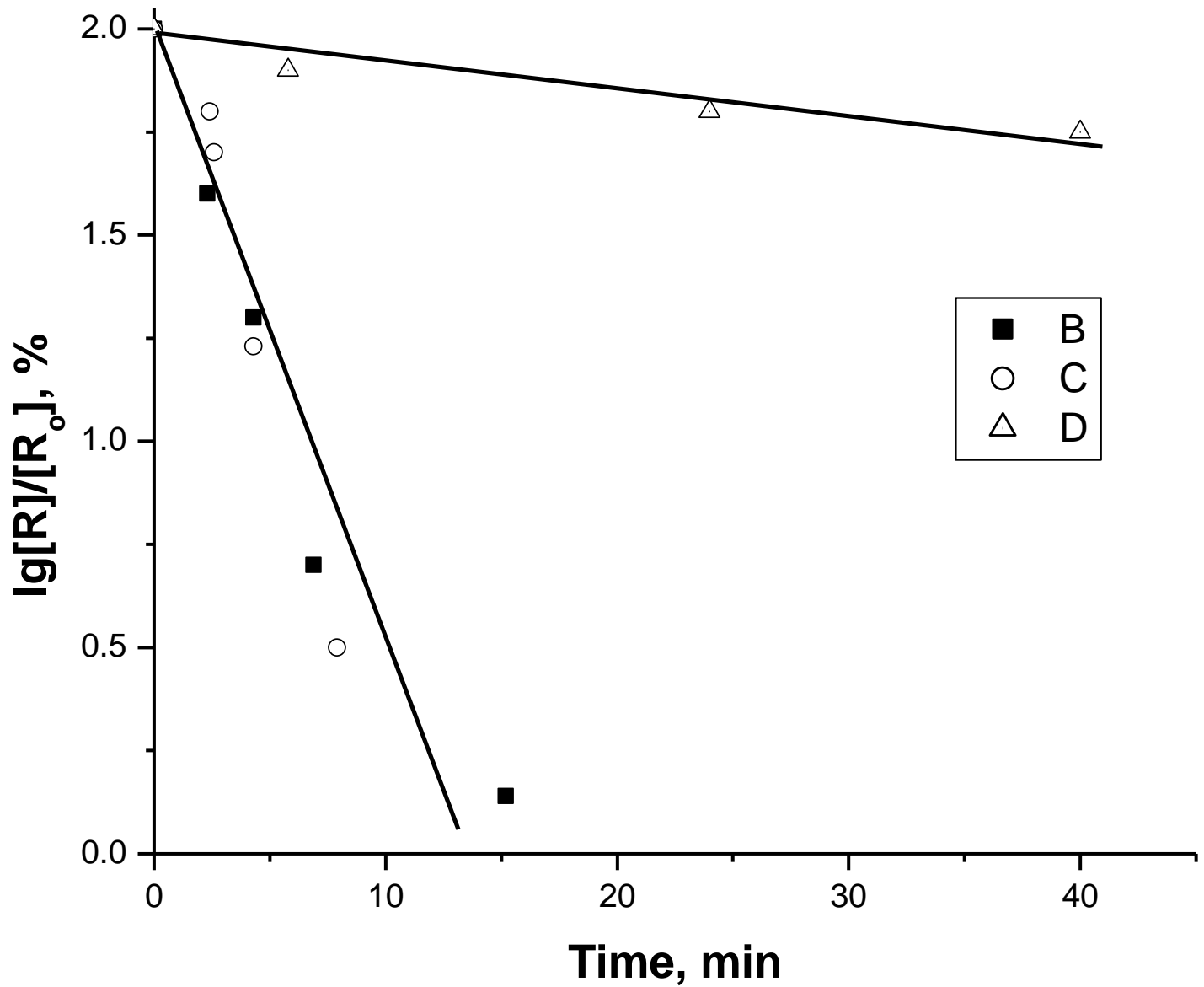

Figure 9. Kinetics of decay of $\mathrm{R}_{\mathrm{F}}{ }^{\bullet}$ versus the UV irradiation time by the open light $(\mathrm{B}, \mathrm{C})$ and by the light with $\lambda \geq 280 \mathrm{~nm}$ (D) of the mercury DRSh-1000 lamp. Curves B,D- obtained by ESR method, C - by optical spectroscopy.

The $\left[\left(\mathrm{CF}_{3}\right)_{2} \mathrm{CF}\right]_{2} \mathrm{C}^{\bullet} \mathrm{C}_{2} \mathrm{~F}_{5}$ radical does not react with monomers under the usual conditions but does decompose under heating or irradiation by UV light. As a result of the decomposition, $\mathrm{CF}_{3}{ }^{\circ}$ radicals are formed, which can initiate chain reactions, for example the polymerization of tetrafluoroethylene [4]:

$$
\begin{aligned}
& {\left[\left(\mathrm{CF}_{3}\right)_{2} \mathrm{CF}_{2} \mathrm{C}^{*} \mathrm{C}_{2} \mathrm{~F}_{5} \rightarrow \text { perfluoroolefin }+\mathrm{C}^{*} \mathrm{~F}_{3}\right.} \\
& \mathrm{CF}_{3}{ }^{\circ}+\mathrm{C}_{2} \mathrm{~F}_{4} \rightarrow \mathrm{CF}_{3} \mathrm{CF}_{2} \mathrm{CF}_{2} \cdot \\
& \mathrm{CF}_{3} \mathrm{CF}_{2} \mathrm{CF}_{2}+\mathrm{nC}_{2} \mathrm{~F}_{4} \rightarrow \mathrm{CF}_{3}\left(\mathrm{CF}_{2} \mathrm{CF}_{2}\right)_{n} \mathrm{CF}_{2} \mathrm{CF}_{2} \cdot
\end{aligned}
$$


Experiments show that effective polymerization of TFE in a solution of $(\mathrm{HFP})_{3}$ in the presence of $\left[\left(\mathrm{CF}_{3}\right)_{2} \mathrm{CF}\right]_{2} \mathrm{C}^{\bullet} \mathrm{C}_{2} \mathrm{~F}_{5}$ occurs only at temperatures where the radicals are decomposing (curves 1 and 2, Figure 10). About $60 \%$ of the TFE can be polymerized during $15 \mathrm{~min}$ if the samples of TFE $(50 \mathrm{~mol} \%)-(\mathrm{HFP})_{3}(50 \mathrm{~mol} \%)$ containing $2 \times 10^{18}$ of $\left[\left(\mathrm{CF}_{3}\right)_{2} \mathrm{CF}\right]_{2} \mathrm{C}^{\bullet} \mathrm{C}_{2} \mathrm{~F}_{5}$ per gram of $\left.(\mathrm{HFP})_{3}\right)$ are heated to $373 \mathrm{~K}$. The polymer does not form on heating samples which do not contain $\left[\left(\mathrm{CF}_{3}\right)_{2} \mathrm{CF}\right]_{2} \mathrm{C}^{\bullet} \mathrm{C}_{2} \mathrm{~F}_{5}$.

In order to search for other fluorocarbon radicals that might be sources of $\mathrm{CF}_{3}{ }^{\bullet}$ radicals, we predicted the BDEs of a number of radicals (Table 1). Of interest is whether there are C-C BDEs in these radicals which are very low. Reactions (8), (9), and (10) have BDEs between 7 and $15 \mathrm{kcal} / \mathrm{mol}$ so the molecule could spontaneously dissociate because of the gain in entropy if there are no additional energy barriers. For example, the presence of a $\mathrm{C}\left(\mathrm{CF}_{3}\right)_{3}$ group can lead to such low BDEs. We also predicted a C-F bond in a radical with a BDE of only $55 \mathrm{kcal} / \mathrm{mol}$ (reaction (16)).

\section{Conclusions}

$\mathrm{UV}$ irradiation of the radical $\left[\left(\mathrm{CF}_{3}\right)_{2} \mathrm{CF}\right]_{2} \mathrm{C}^{\bullet} \mathrm{C}_{2} \mathrm{~F}_{5}$ in a $(\mathrm{HFP})_{3}$ glassy matrix at $77 \mathrm{~K}$ and in a $(\mathrm{HFP})_{3}$ solution at $300 \mathrm{~K}$ leads to decomposition to the $\mathrm{CF}_{3} \cdot$ radical and a perfluoro-olefin. About $90 \%$ of the ${ }^{\bullet} \mathrm{CF}_{3}$ radicals formed recombine at $300 \mathrm{~K}$. The remaining radicals add to the $(\mathrm{HFP})_{3}$ molecules generating the long-lived radicals $\left[\left(\mathrm{CF}_{3}\right)_{2} \mathrm{CF}\right]_{3} \mathrm{C}^{\bullet}$. Three types of photosensitive centers which are stable in a liquid and have different lifetimes at $300 \mathrm{~K}$ were observed in the optical absorption spectrum of (HFP) ${ }_{3}$ undergoing radiolysis. 


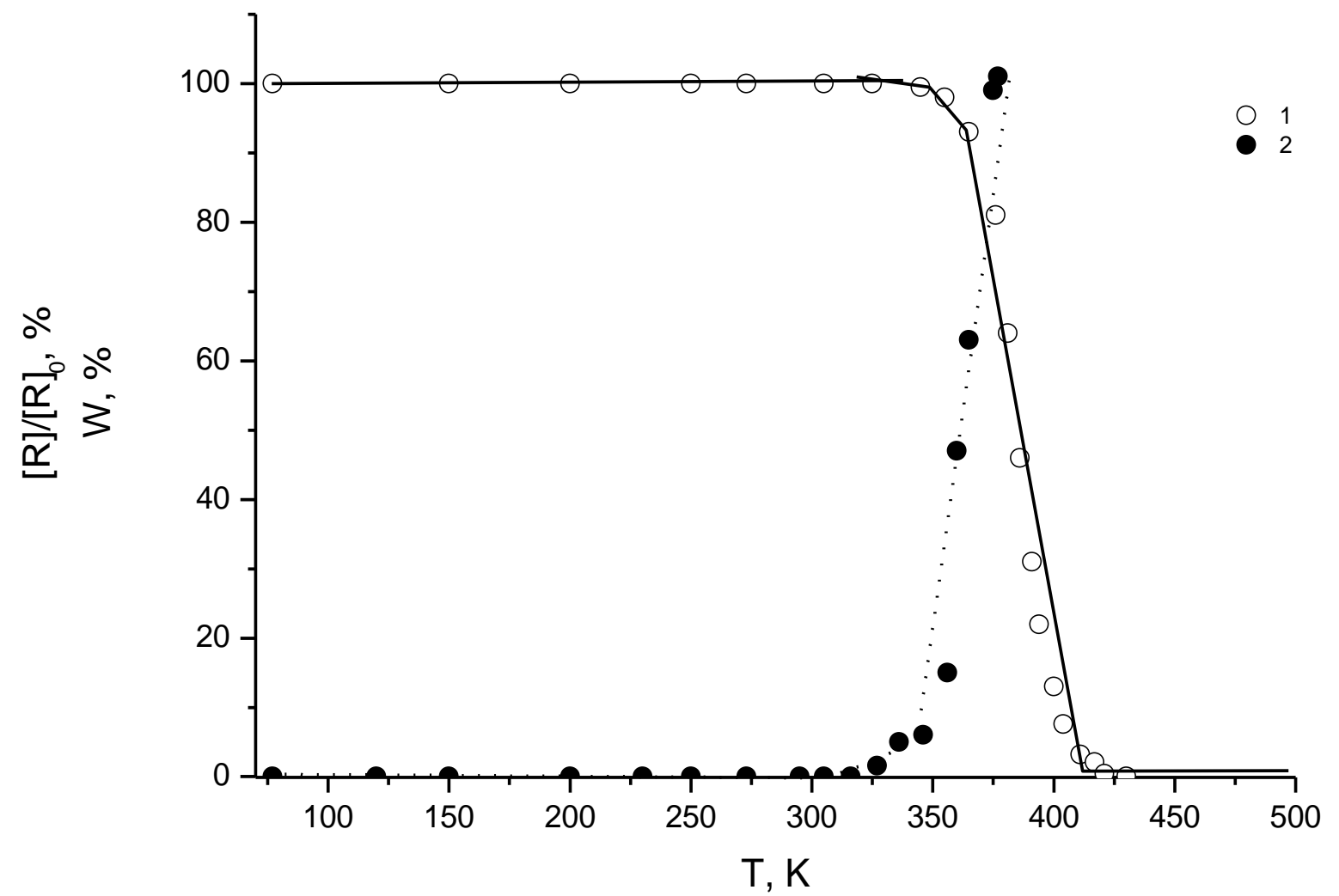

Figure 10. Dependence of concentration of $\mathrm{R}_{\mathrm{F}}{ }^{\circ}(1)$ and the polymer yield (2) from temperature at heating of TFE in the liquid $(\mathrm{HFP})_{3}$ at presence of radicals $\left[\mathrm{R}_{\mathrm{F}}{ }^{\bullet}\right]=2 \times 10^{18}$ in 1 gram of $(\mathrm{HFP})_{3}$.

A difference in the mechanisms of photo-induced and thermal decomposition of $\mathrm{RF}^{\bullet}$ radical was demonstrated by comparing the experimental results with calculated BDEs and UVvis spectra. Irradiation with light of $<320 \mathrm{~nm}$ results in a transition of the radical to an excited state followed by rupture of the $\mathrm{CF}_{2}-\mathrm{CF}_{3}$ bond in the perfluoroethyl group. In the thermal degradation of this radical (heating up to $373 \mathrm{~K}$ ), the rupture $\mathrm{CF}_{3}-\mathrm{CF}$ bonds in the perfluoroisopropyl group is more favorable because the BDE for this bond is $4 \mathrm{kcal} / \mathrm{mol}$ smaller as compared to the $\mathrm{CF}_{2}-\mathrm{CF}_{3}$ bond in the perfluoro-ethyl group.

The available data show that $\left[\left(\mathrm{CF}_{3}\right)_{2} \mathrm{CF}\right]_{2} \mathrm{C}^{\bullet} \mathrm{C}_{2} \mathrm{~F}_{5}$ is chemically stable at room temperature and does not react with anything except fluorine or electron transfer agents.[5] Hence, activation 
of $\left[\left(\mathrm{CF}_{3}\right)_{2} \mathrm{CF}\right]_{2} \mathrm{C}^{\bullet} \mathrm{C}_{2} \mathrm{~F}_{5}$ to yield radicals for use in chemical reactions such as polymerization requires heating, $\mathrm{UV}$ light, or radiolysis. This activation can yield $\mathrm{CF}_{3}{ }^{\circ}$ radicals which can behave in different ways. For example, unlike the $\mathrm{CF}_{3}{ }^{\bullet}$ radicals produced by the photodecomposition of $\left[\left(\mathrm{CF}_{3}\right)_{2} \mathrm{CF}\right]_{2} \mathrm{C}^{\bullet} \mathrm{C}_{2} \mathrm{~F}_{5}$, the $\mathrm{CF}_{3}$ radicals formed during radiolysis of $(\mathrm{HFP})_{3}$ are not stabilized in the glassy $(\mathrm{HFP})_{3}$ matrix at $77 \mathrm{~K}$. We calculated $\mathrm{C}-\mathrm{C}$ BDEs for a number of fluorocarbon radicals and showed that radicals can be designed with very low C-C BDEs leading to the generation of $\mathrm{CF}_{3}{ }^{\bullet}$ radicals, potentially at room temperature, which could then be used in radical reactions.

\section{Experimental and Computational}

The samples of $(\mathrm{HFP})_{3}$ contained two isomers $\left[\left(\mathrm{CF}_{3}\right)_{2} \mathrm{CF}\right]_{2} \mathrm{C}=\mathrm{CFCF}_{3} \quad(47 \%)$ and $\left(\mathrm{CF}_{3}\right)_{2} \mathrm{CF}_{2} \mathrm{C}\left(\mathrm{C}_{2} \mathrm{~F}_{5}\right)=\mathrm{C}\left(\mathrm{CF}_{3}\right)_{2}(53 \%)$. The solution containing $3 \times 10^{20} \mathrm{~g}^{-1}$ of $\left[\left(\mathrm{CF}_{3}\right)_{2} \mathrm{CF}\right]_{2} \mathrm{C}^{\bullet} \mathrm{C}_{2} \mathrm{~F}_{5}$ in $(\mathrm{HFP})_{3}$ was obtained as described previously. [9] To prepare $\left[\left(\mathrm{CF}_{3}\right)_{2} \mathrm{CF}\right]_{2} \mathrm{C}^{\bullet} \mathrm{C}_{2} \mathrm{~F}_{5}$, the samples of $(\mathrm{HFP})_{3}$ were evacuated to a pressure of $0.13 \mathrm{~Pa}$ and were $\gamma$-irradiated using a ${ }^{60} \mathrm{Co}$ source at $77 \mathrm{~K}$ to a dose of $1.4 \mathrm{MGy}$. The irradiated samples were warmed to $300 \mathrm{~K}$ and maintained at this temperature for a month. The concentration of $\left[\left(\mathrm{CF}_{3}\right)_{2} \mathrm{CF}\right]_{2} \mathrm{C}^{\bullet} \mathrm{C}_{2} \mathrm{~F}_{5}$ was $3 \times 10^{20} \mathrm{~g}^{-1}$ and the radicals were stable for many years in air and can be distilled at $387 \mathrm{~K}$. The samples with smaller concentrations of $\left[\left(\mathrm{CF}_{3}\right)_{2} \mathrm{CF}\right]_{2} \mathrm{C}^{\bullet} \mathrm{C}_{2} \mathrm{~F}_{5}$ were prepared by dilution of the solution containing $3 \times 10^{20} \mathrm{~g}^{-1}$ radicals with the initial $(\mathrm{HFP})_{3}$.

ESR spectra were recorded on spectrometers of trade mark "EPR-21" and " PS100.X". The uncertainty in the determination of absolute concentration of paramagnetic species by "EPR21 " was $20-30 \%$, and the relative experimental error did not exceed $5-10 \%$. The smaller PS100.X spectrometer uses the "EPRWIN" program for processing the ESR spectra 
automatically. The theoretical simulation was performed with the use of the 'EPRTOOLS' program (software developer, NPP “Adani”, Minsk).

The samples were irradiated with UV light in quartz ampules of 4 to $5 \mathrm{~mm}$ diameter under vacuum at $77 \mathrm{~K}$. A high-pressure mercury lamp of trade mark "DRSh-1000" was used as the UV light source with a continuous spectrum of radiation in the range $210-750 \mathrm{~nm}$. The samples were irradiated for $10 \mathrm{~min}$ at each experimental temperature.

Optical absorption spectra were recorded on "Specord" and "Cary-14" spectrophotometers (the "Cary-14" allows recording to $185 \mathrm{~nm}$ ). Sample preparation and measurements of the optical absorption spectra were carried out using a standard procedure [19].

Irradiation of the HFP samples with $\gamma$-rays was performed on a ${ }^{60} \mathrm{Co}$ Gammatok-100 facility in the vacuum at $77 \mathrm{~K}$ in the ampules made from glass of trade mark "SK- $4 \mathrm{~b}$ ". This glass does not give an ESR signal upon $\gamma$-radiolysis. The dose rate was $0.5 \mathrm{kGy} / \mathrm{h}$. The dosimetry of the $\gamma$-source was performed using the standard ferrous sulfate method.

Electronic structure calculations of a range of radicals and closed shell molecules relevant to the irradiation of $(\mathrm{HFP})_{3}$ were performed at the B3LYP/DZVP2 level of density functional theory. $[14,15,16]$ All calculations were done with the Gaussian09 program system. [20] Acknowledgement The authors thank the U.S. Civilian Research and Development Foundation for financial support (Grant RUC1-7093-MO-13). D. A. Dixon thanks the Robert Ramsay fund of The University of Alabama for partial support. The electronic structure calculations were supported by the US Department of Energy, Office of Basic Energy Sciences.

\section{References}

[1] A. L. Buchachenko, A. M. Vasserman, Stabilnie Radikali (Stable radicals), Chemistry: Moscow, 1973, 408 pp. (in Russian). 
[2] S. R. Allayarov, I. M. Barkalov, V. I. Gol'danskii, D. P. Kirjuhin, Bull. Acad. Sci. USSR, Div. Chem. Sci., 32 (1983) 1105-1107.

[3] K. V. Scherer, T. Ono, K. Yamanouchi, R. E. Fernandez, P. Henderson, H. Goldwhite, J. Amer. Chem. Soc. 107 (1985) 718-719.

[4] S. R. Allayarov, Doctor of Chemical Sciences Dissertation. Institute of Chemical Physics of the Academy of Sciences of the USSR, Moscow, 1993, $361 \mathrm{pp}$.

[5] P. B. Henderson, PhD. Dissertation University of Southern California. 1987, 211 pp.

[6] B. L. Tumanskii, T. V. Timofeeva, L. L. Gervits, K. N. Makarov, Yu. T. Struchkov, S. P. Solodovnikov, N. N. Bubnov, Bull. Acad. Sci. USSR, Div. Chem. Sci., 40 (1991) 1330-1334.

[7] R. E. Fernandez, PhD. Dissertation University of Southern California. 1987, 215 pp.

[8] S. R. Allayarov, S. V. Konovalihin, D. A. Gordon, T. E. Chernisheva, I. M. Barkalov, High Energy Chemistry, 36 (2002) 405-407.

[9] S. R. Allayarov, A. I. Mikhailov, Russ. Chem. Bull., 50 ( 2001) 1198-1200.

[10] D. A. Gordon, S. R. Allayarov, S. I. Kuzina, I. M. Barkalov, Bull. Acad. Sci. USSR, Div. Chem. Sci., 38 (1989) 2021-2025.

[11] T. Ono, Y. Hayakawa, H. Yokoyama, Proceeding of International Symposium on Eco Topia Science, (2007) 85 .

[12] F. Boschet, T. Ono, B. Ameduri, Macromol. Rapid Comm., 33 (2012) 302-308.

[13] B. E. Smart, P. J. Krusic, P. Veakin, R. C. Bingham, J. Amer. Chem. Soc., 96( 1974) 73827383.

[14] A. D. Becke, J. Chem. Phys. 98 (1993) 5648-5652.

[15] C. Lee, W. Yang, R. G. Parr, Phys Rev B. 37 (1988) 785-789.

[16] N. Godbout, D. R. Salahub, J. Andzelm, E. Wimmer, Can. J. Chem. 70, (1992) 560-571. 
[17] L. A. Curtiss, P. C. Redfern, K. Raghavachari, J. Chem. Phys. 126 (2007) 084018 (12 pages).

[18] S. R. Allayarov, I. P. Kim, V. E. Jackson, D. A. Dixon, J. Fluorine Chem. Submitted. [19] V.V. Lebedeva, Tehnika opticheskoi spektroskopii (Technique of Optical Spectroscopy), MGU: Moscow, 1986, 352 pp. (in Russian).

[20] Gaussian 09, Revision D.01, M. J. Frisch, G. W. Trucks, H. B. Schlegel, G. E. Scuseria, M. A. Robb, J. R. Cheeseman, G. Scalmani, V. Barone, B. Mennucci, G. A. Petersson, H. Nakatsuji, M. Caricato, X. Li, H. P. Hratchian, A. F. Izmaylov, J. Bloino, G. Zheng, J. L. Sonnenberg, M. Hada, M. Ehara, K. Toyota, R. Fukuda, J. Hasegawa, M. Ishida, T. Nakajima, Y. Honda, O. Kitao, H. Nakai, T. Vreven, J. A. Montgomery, Jr., J. E. Peralta, F. Ogliaro, M. Bearpark, J. J. Heyd, E. Brothers, K. N. Kudin, V. N. Staroverov, R. Kobayashi, J. Normand, K. Raghavachari, A. Rendell, J. C. Burant, S. S. Iyengar, J. Tomasi, M. Cossi, N. Rega, J. M. Millam, M. Klene, J. E. Knox, J. B. Cross, V. Bakken, C. Adamo, J. Jaramillo, R. Gomperts, R. E. Stratmann, O. Yazyev, A. J. Austin, R. Cammi, C. Pomelli, J. W. Ochterski, R. L. Martin, K. Morokuma, V. G. Zakrzewski, G. A. Voth, P. Salvador, J. J. Dannenberg, S. Dapprich, A. D. Daniels, Ö. Farkas, J. B. Foresman, J. V. Ortiz, J. Cioslowski, and D. J. Fox, Gaussian, Inc., Wallingford CT, 2009. 

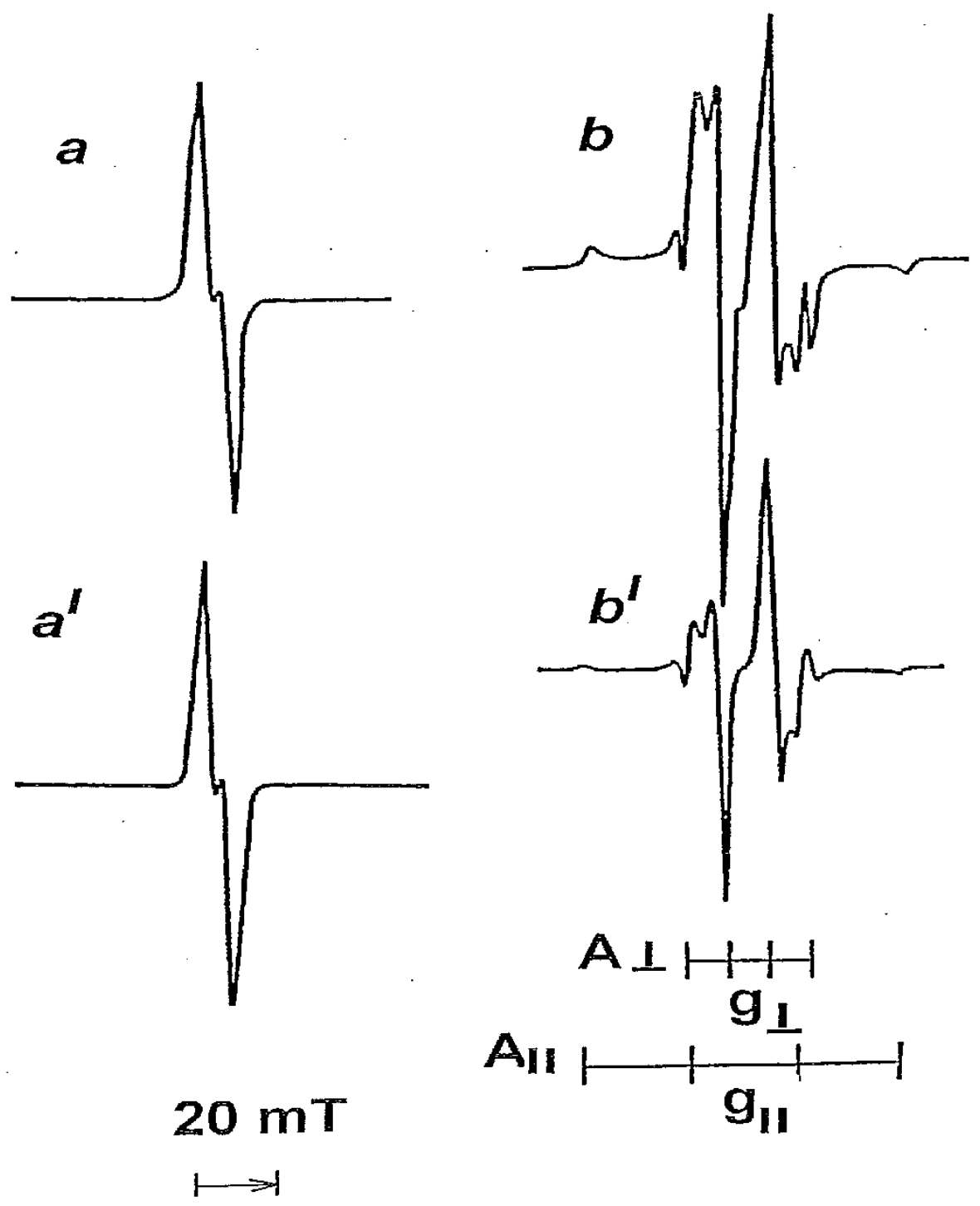

Figure 1. ( $a, b)$ Experimental and (a', b') simulated ESR spectra of the $\mathrm{R}_{\mathrm{F}}{ }^{\bullet}$ radicals in a glassy matrix of $(\mathrm{HFP})_{3}$ observed $\left(\mathrm{a}, \mathrm{a}^{\prime}\right)$ before and $\left(\mathrm{b}, \mathrm{b}^{\prime}\right)$ after $800 \mathrm{~min} \mathrm{UV}$ photolysis at $77 \mathrm{~K}$. The stick diagram for the ${ }^{\bullet} \mathrm{CF}_{3}$ radical spectrum is shown below spectrum $b$ '. 


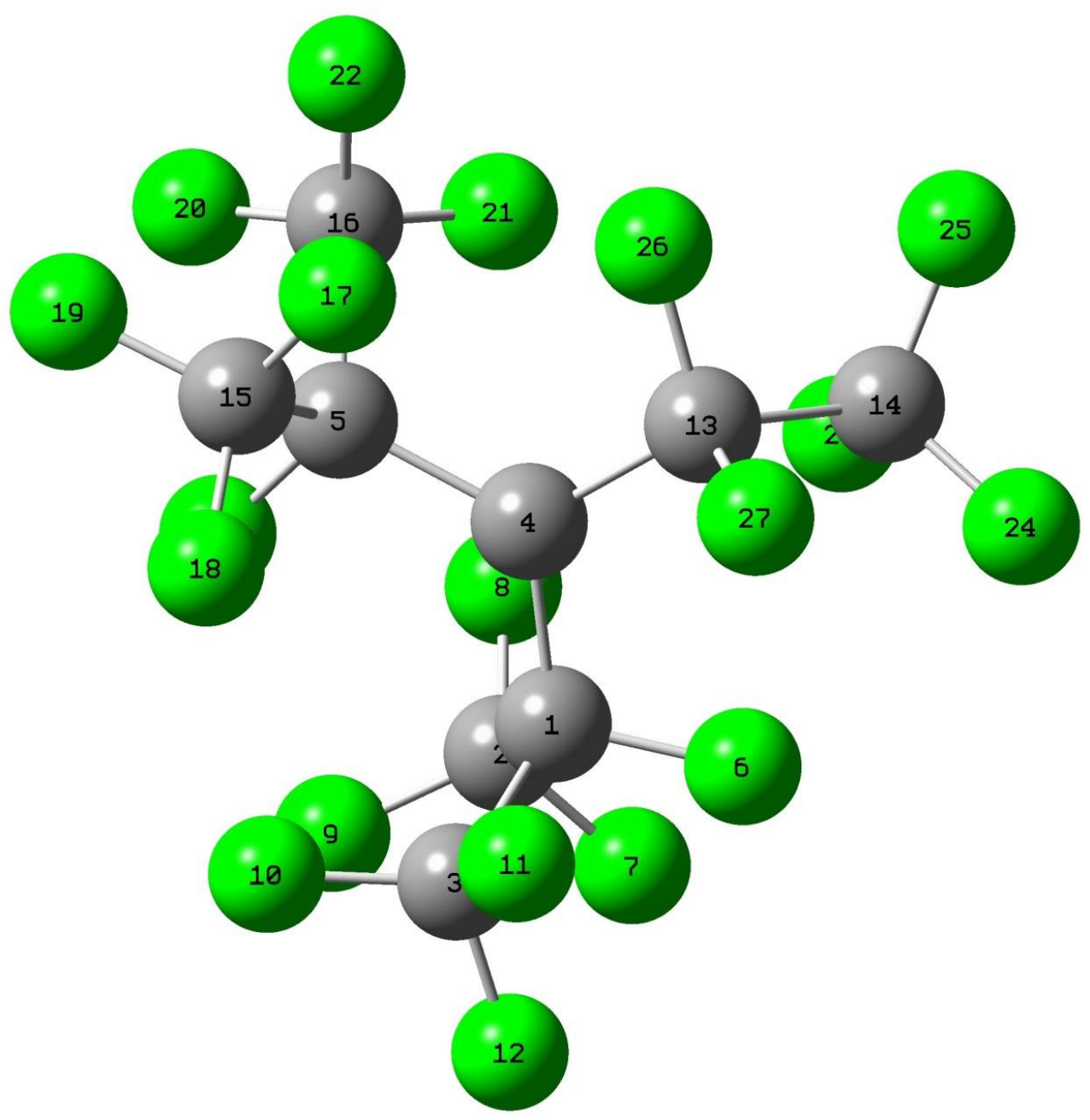

Figure 2. Optimized structure of $\mathrm{R}_{\mathrm{F}}{ }^{\bullet}(\mathrm{I}),\left[\left(\mathrm{CF}_{3}\right)_{2} \mathrm{CF}\right]_{2} \mathrm{C}^{\bullet} \mathrm{C}_{2} \mathrm{~F}_{5}$, at the B3LYP/DZVP2 level. 

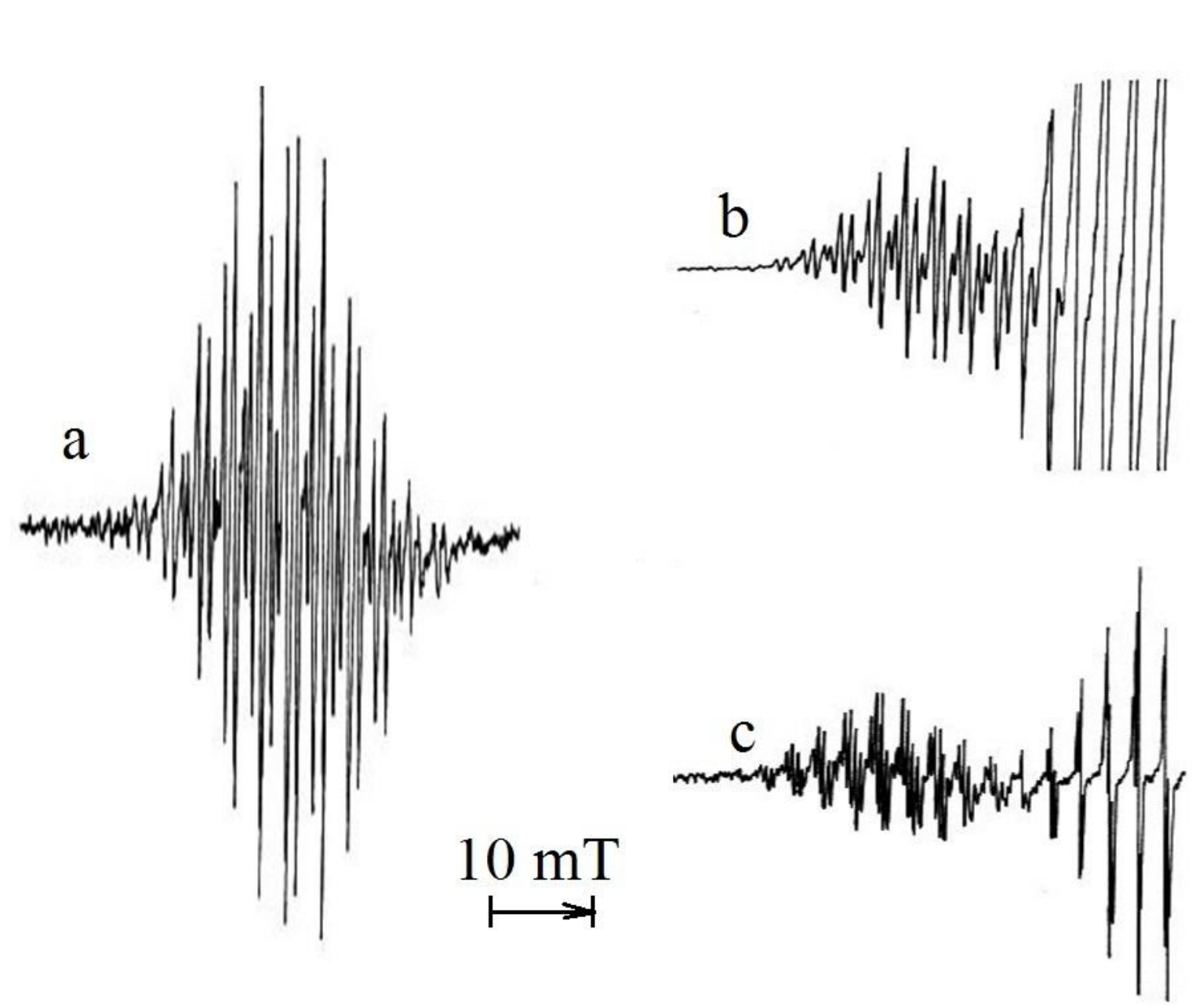

Figure 3 
Figure 4
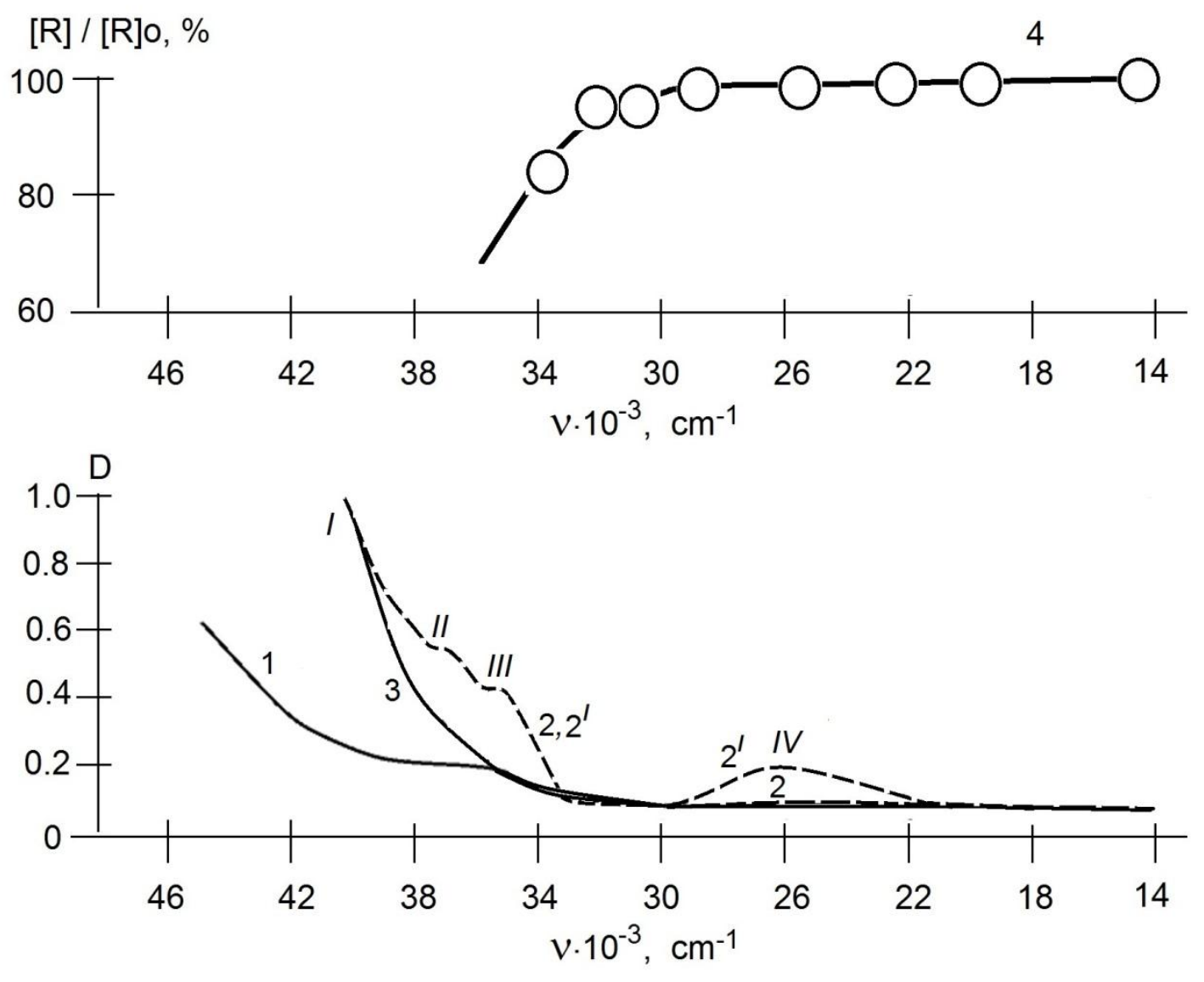

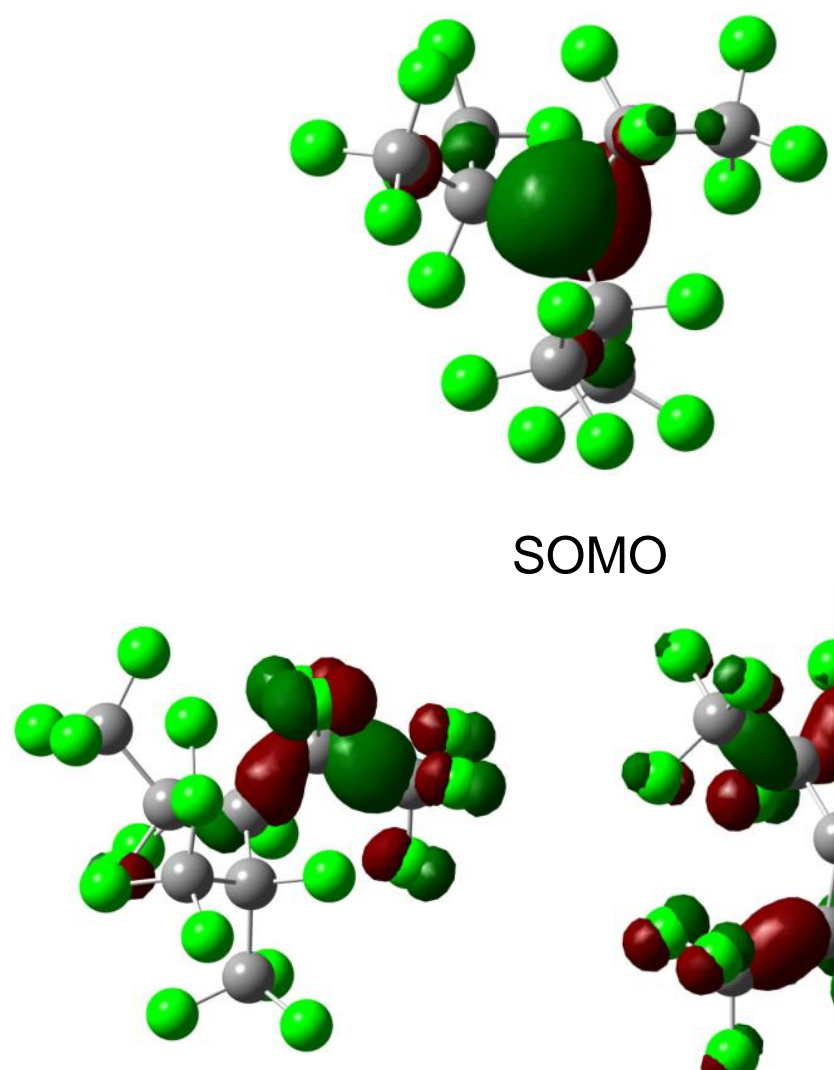

SOMO

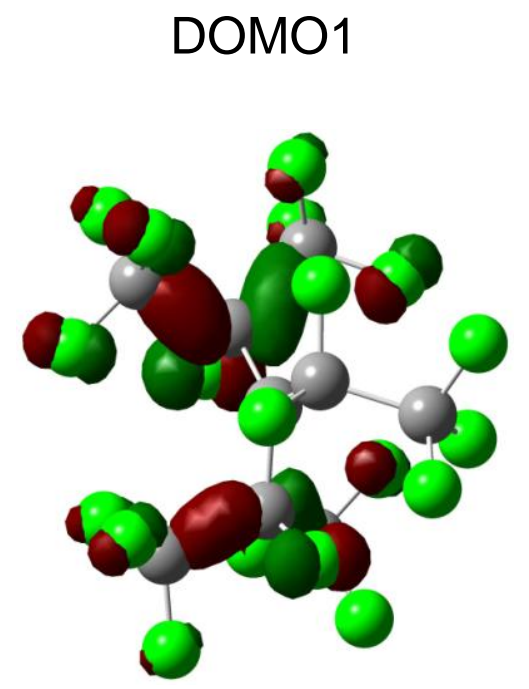

$\mathrm{DOMO} 3$

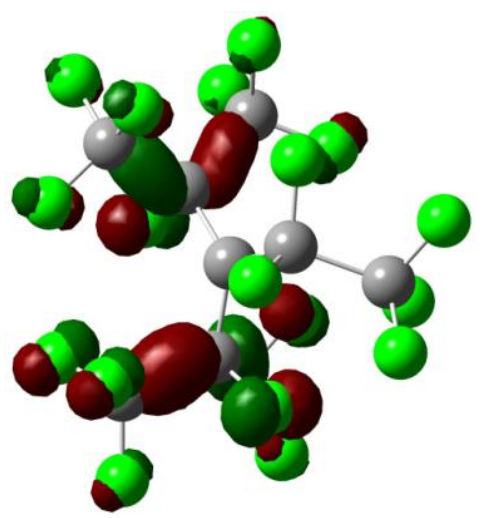

DOMO2

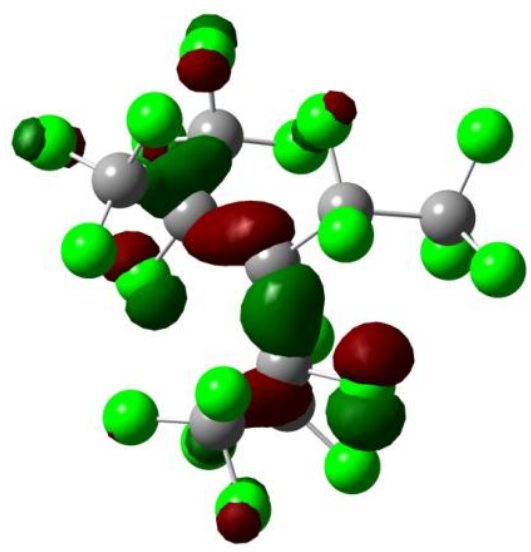

$\mathrm{DOMO} 4$

Figure 5. High lying molecular orbitals of $\left[\left(\mathrm{CF}_{3}\right)_{2} \mathrm{CF}_{2} \mathrm{C}^{\bullet} \mathrm{C}_{2} \mathrm{~F}_{5}\right.$. 


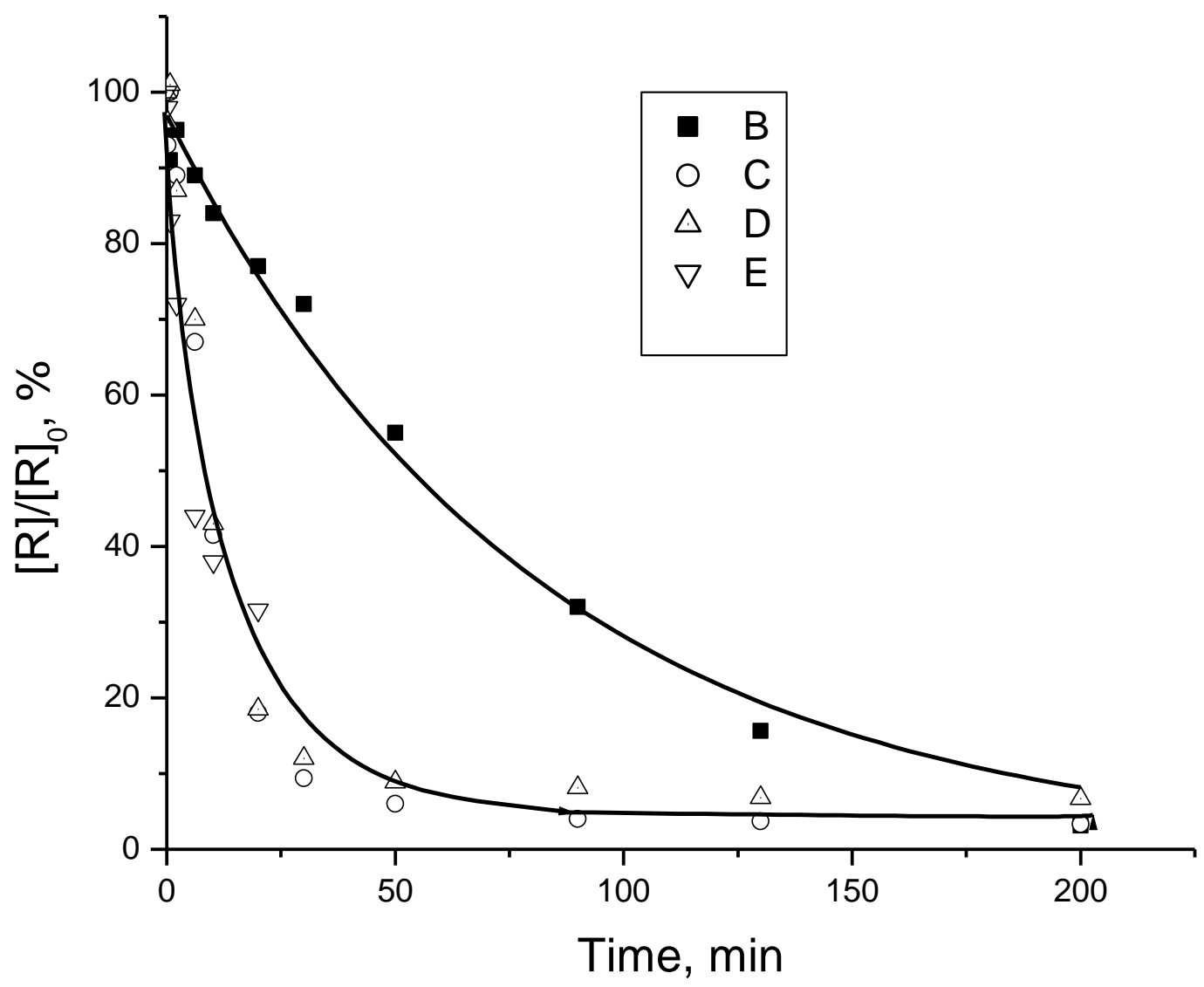

Figure 6. Concentration of radicals in liquid phase versus UV irradiation time at $300 \mathrm{~K}$, containing $3 \times 10^{20}(\mathrm{~B}), 6 \times 10^{18}(\mathrm{C}), 3 \times 10^{18}(\mathrm{D})$ and $6 \times 10^{17} \mathrm{~g}^{-1}(\mathrm{E})$ of $\mathrm{R}_{\mathrm{F}}{ }^{\bullet}$ in the liquid (HFP) ${ }_{3}$. 


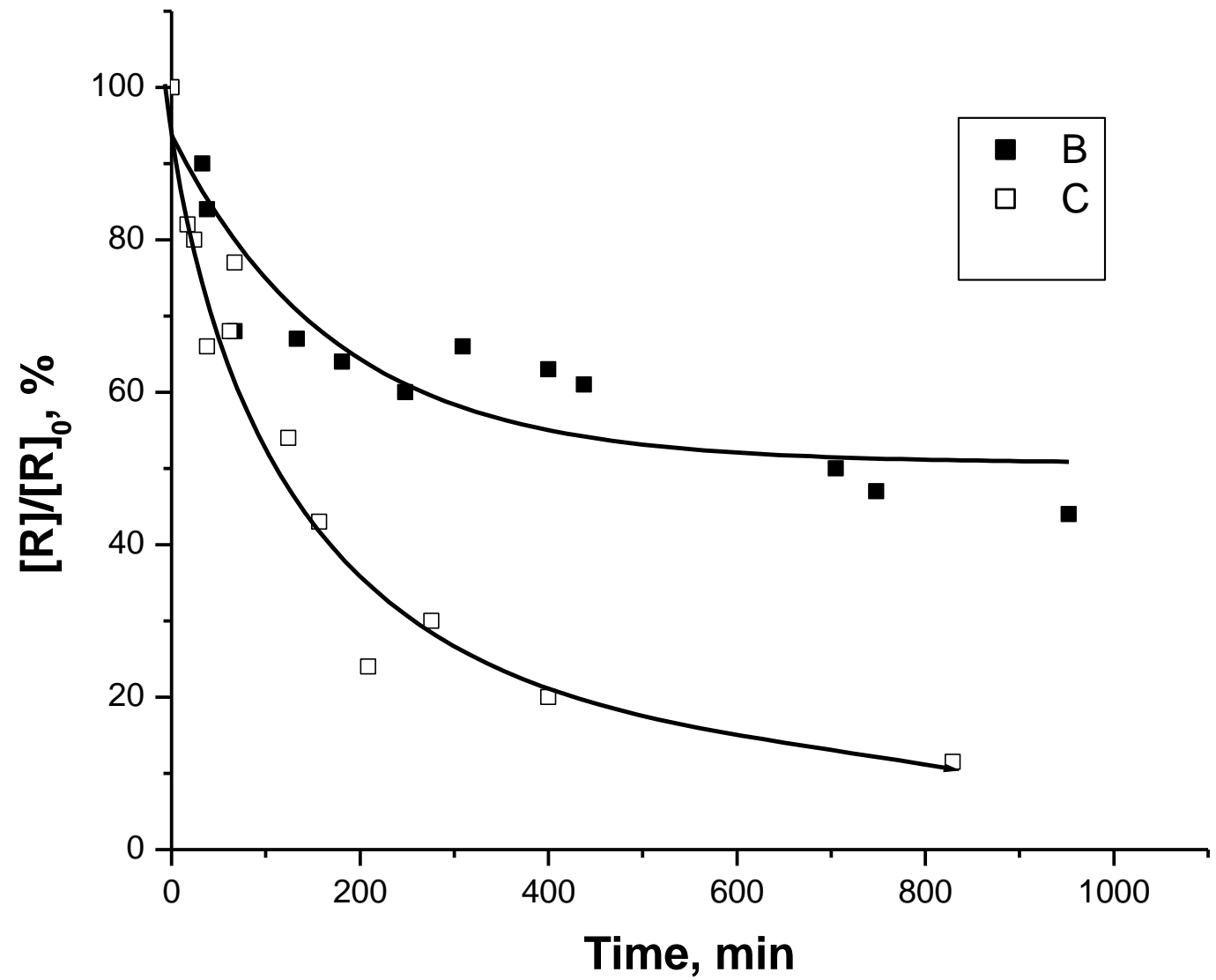

Figure 7. Concentration of radicals $R_{F}{ }^{\bullet}$ in a glassy matrix versus UV irradiation time at $77 \mathrm{~K}$, containing $3 \times 10^{20}(\mathrm{~B})$ and $6 \times 10^{17} \mathrm{~g}^{-1}(\mathrm{C})$ of $\mathrm{R}_{\mathrm{F}}$. 


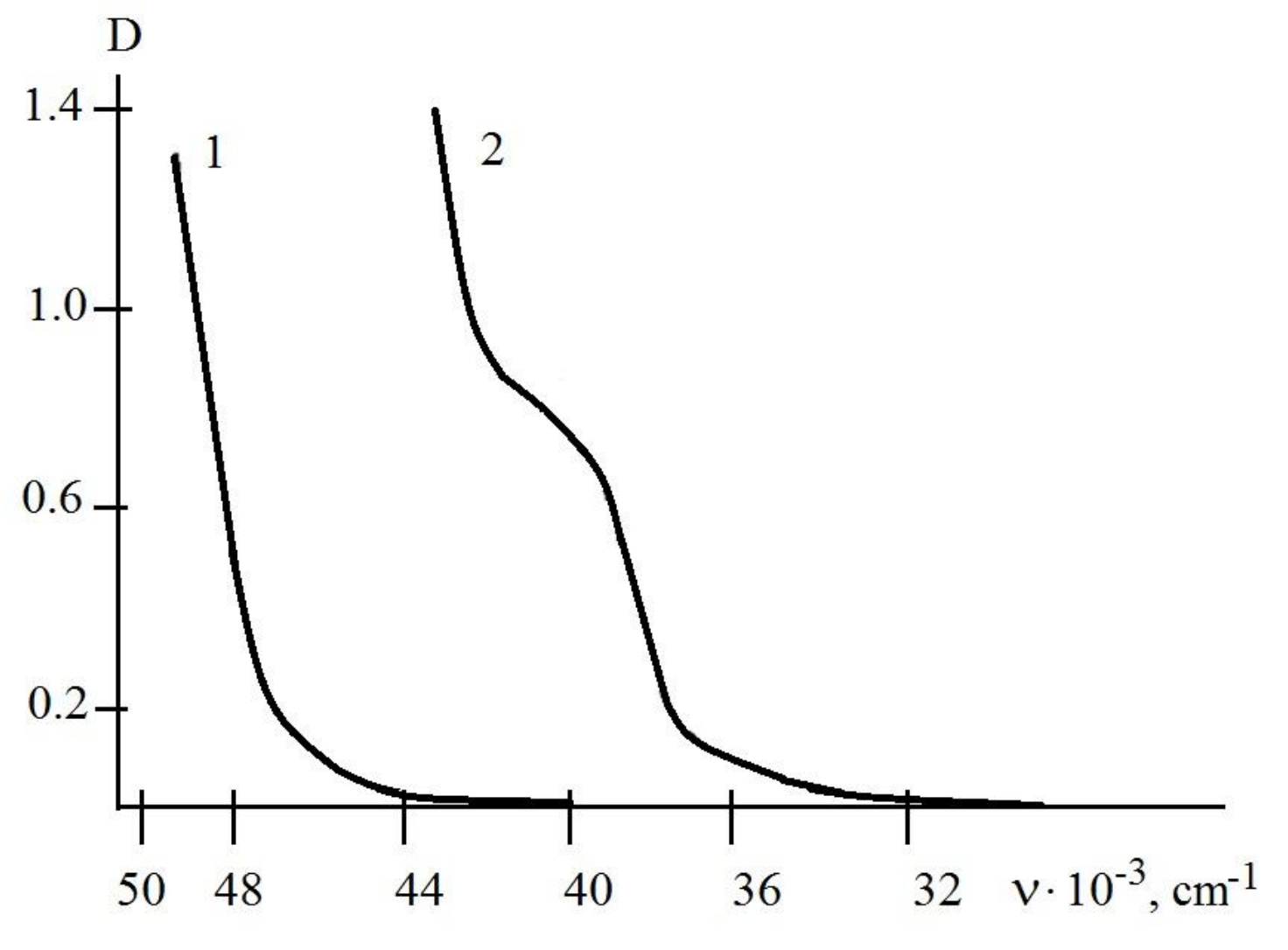

Figure 8 


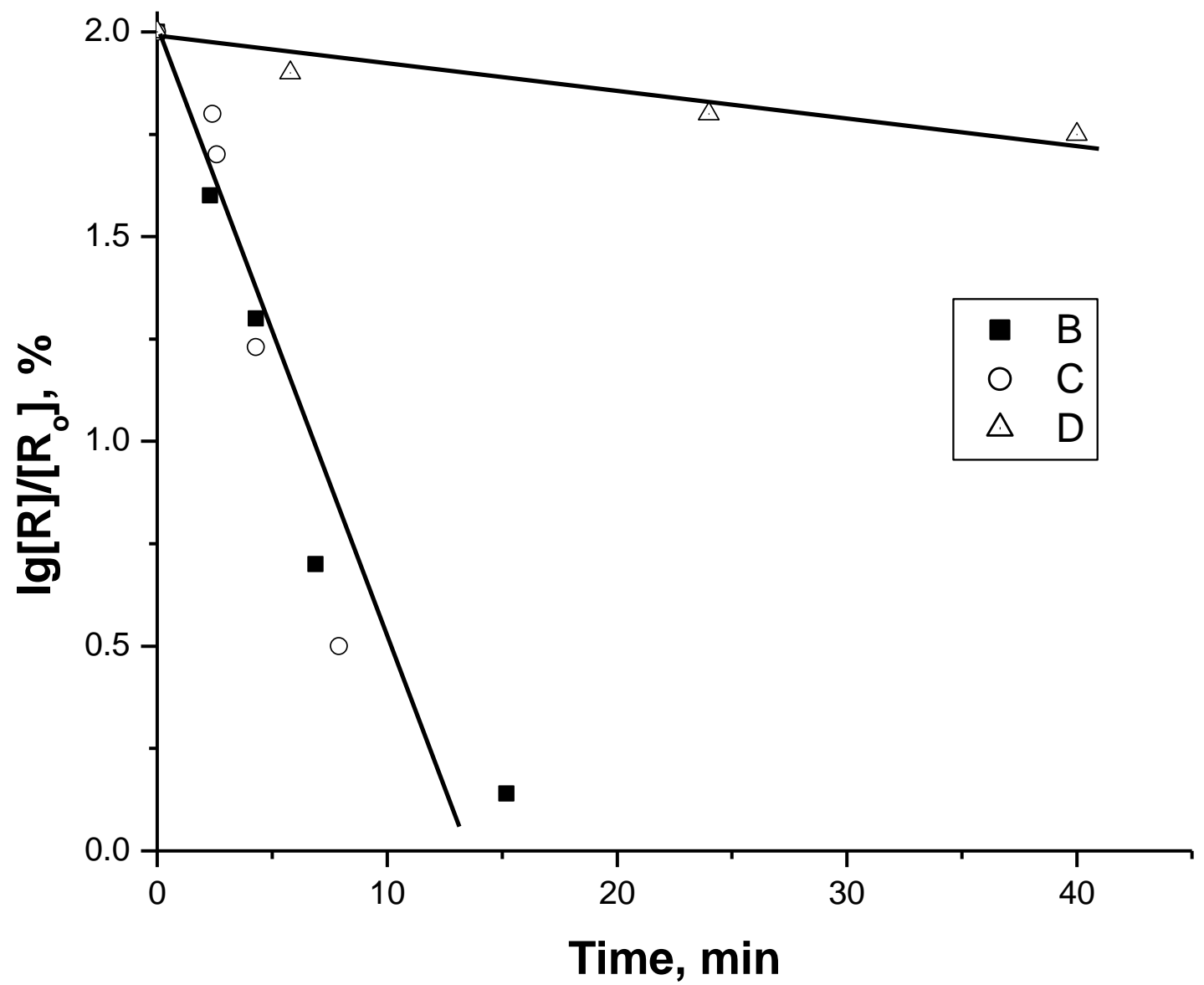

Figure 9. Kinetics of decay of $\mathrm{R}_{\mathrm{F}}{ }^{\bullet}$ versus the UV irradiation time by the open light $(\mathrm{B}, \mathrm{C})$ and by the light with $\lambda \geq 280 \mathrm{~nm}$ (D) of the mercury DRSh-1000 lamp. Curves B,D- obtained by ESR method, C - by optical spectroscopy. 


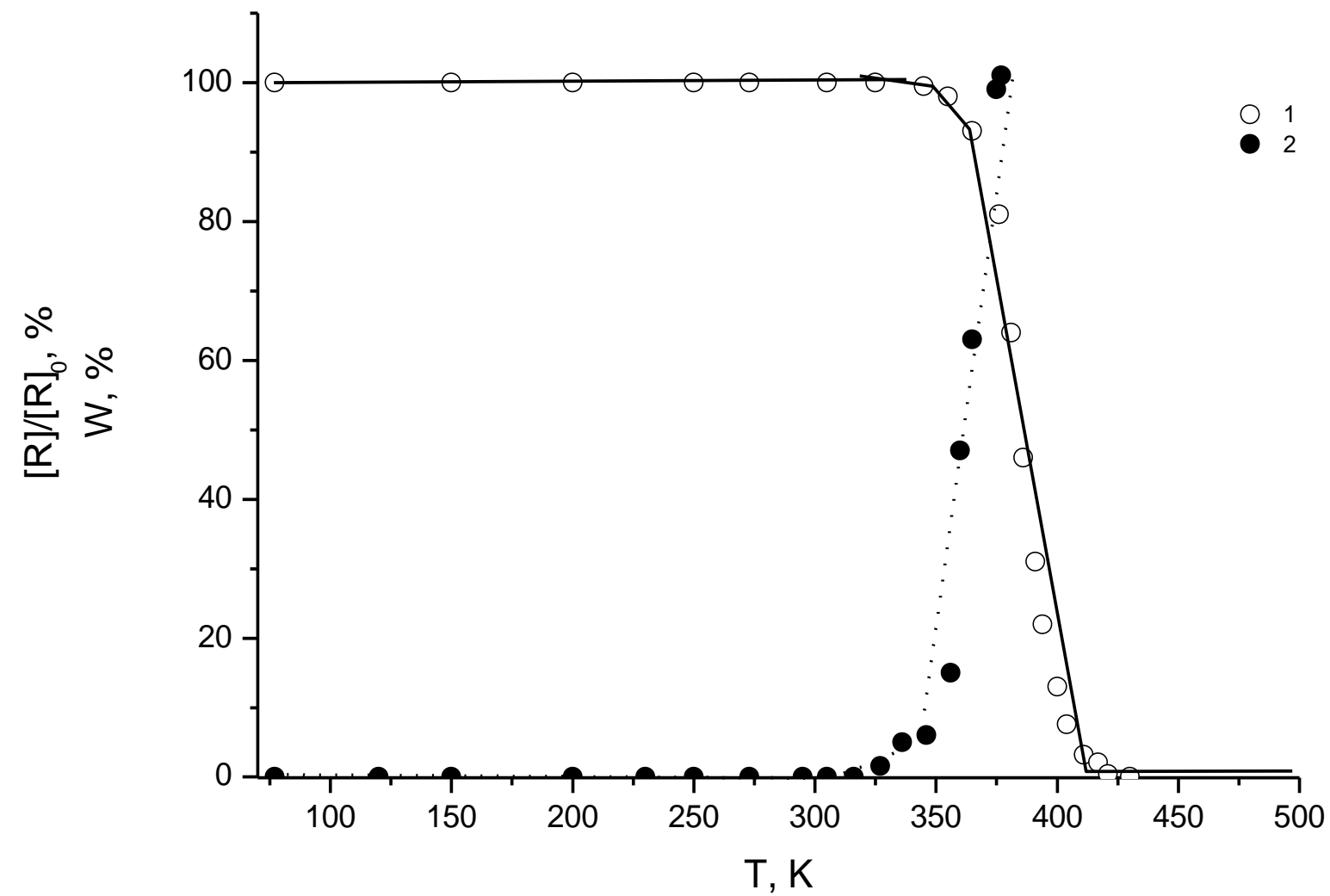

Figure 10. Dependence of concentration of $\mathrm{R}_{\mathrm{F}}{ }^{\bullet}(1)$ and the polymer yield (2) from temperature at heating of TFE in the liquid $(\mathrm{HFP})_{3}$ at presence of radicals $\left[\mathrm{R}_{\mathrm{F}}{ }^{\bullet}\right]=2 \times 10^{18}$ in 1 gram of $(\mathrm{HFP})_{3}$. 
Table 1. Corrected B3LYP Reaction Energies in kcal/mol for Perfluorocarbon Chains. ${ }^{\text {a }}$

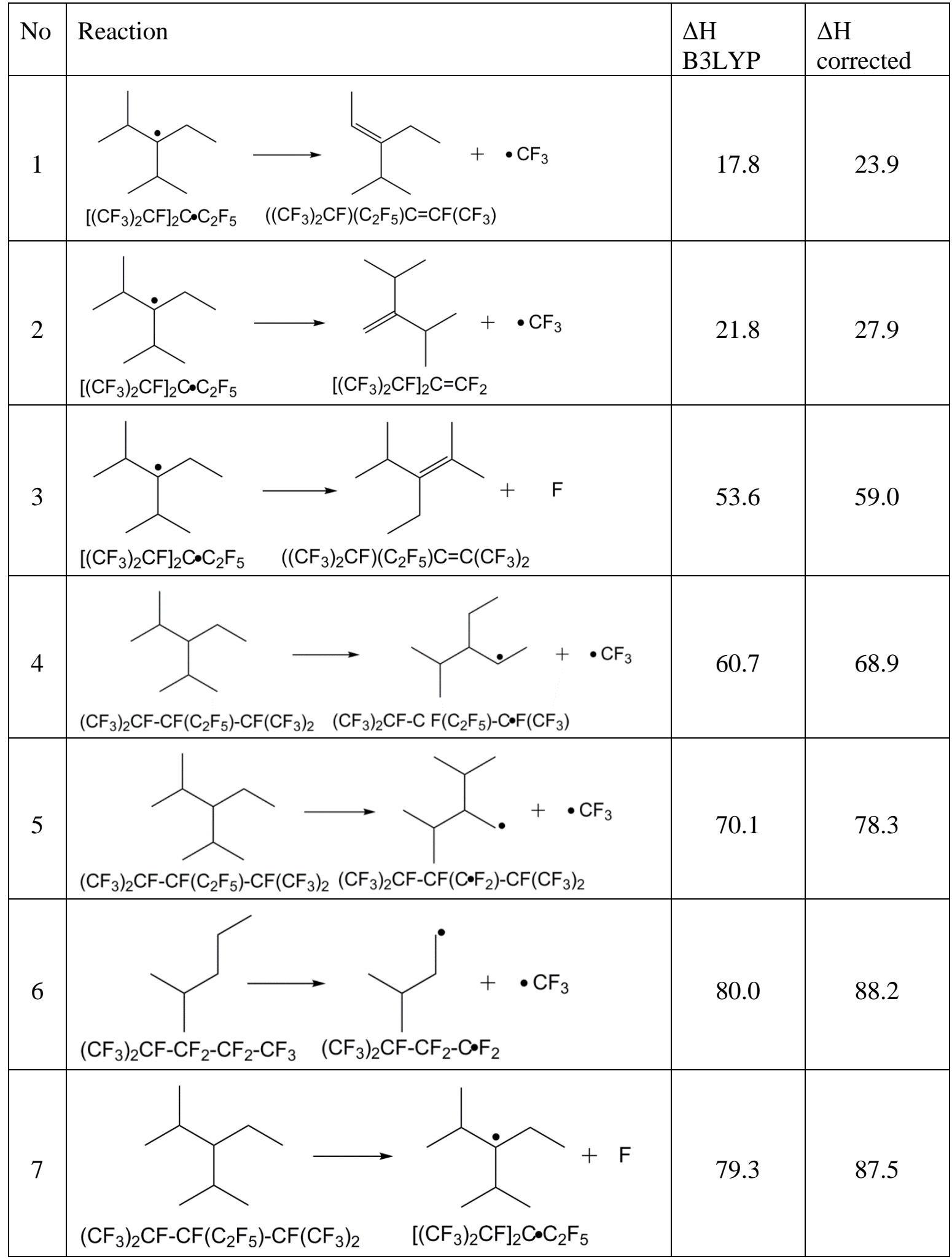




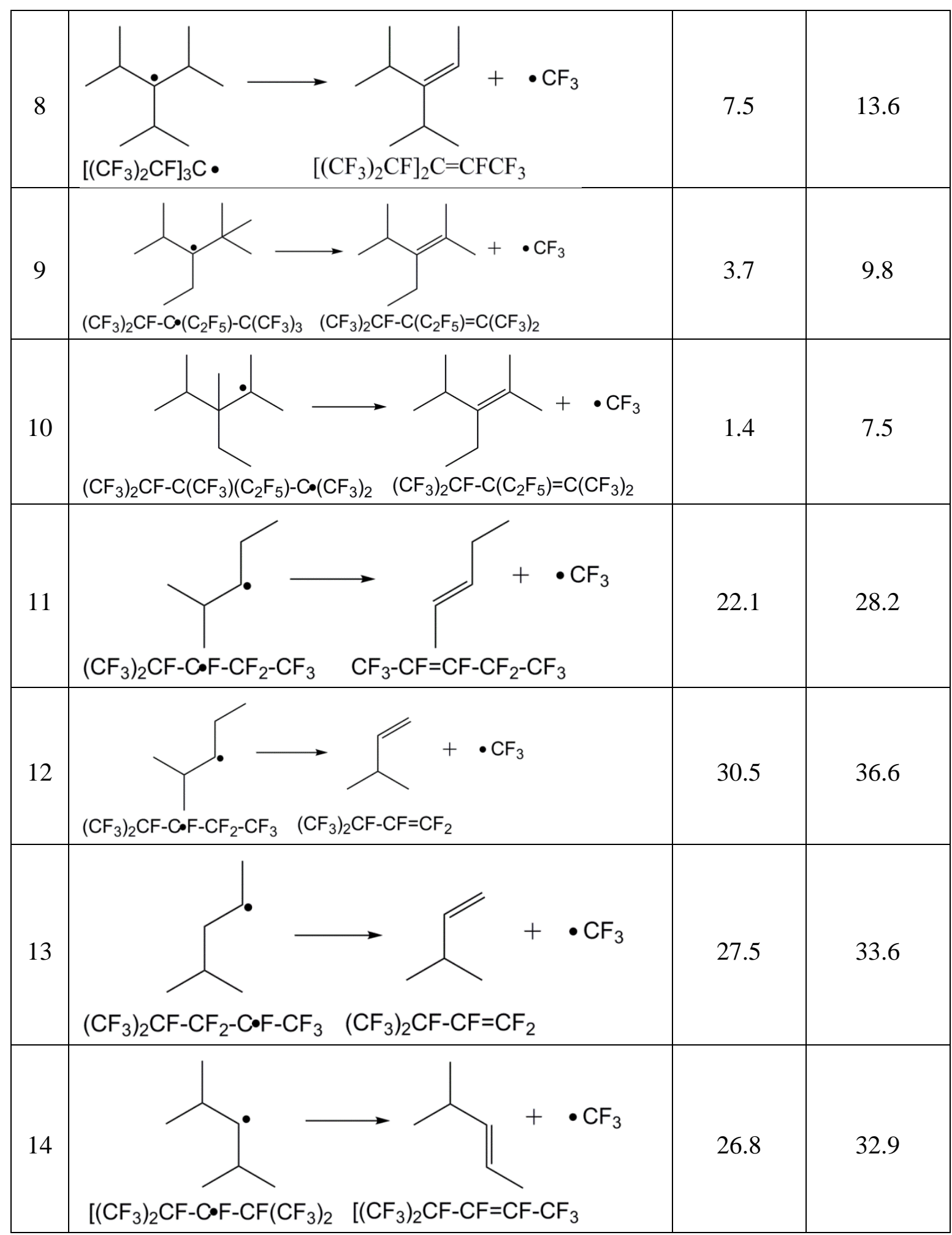




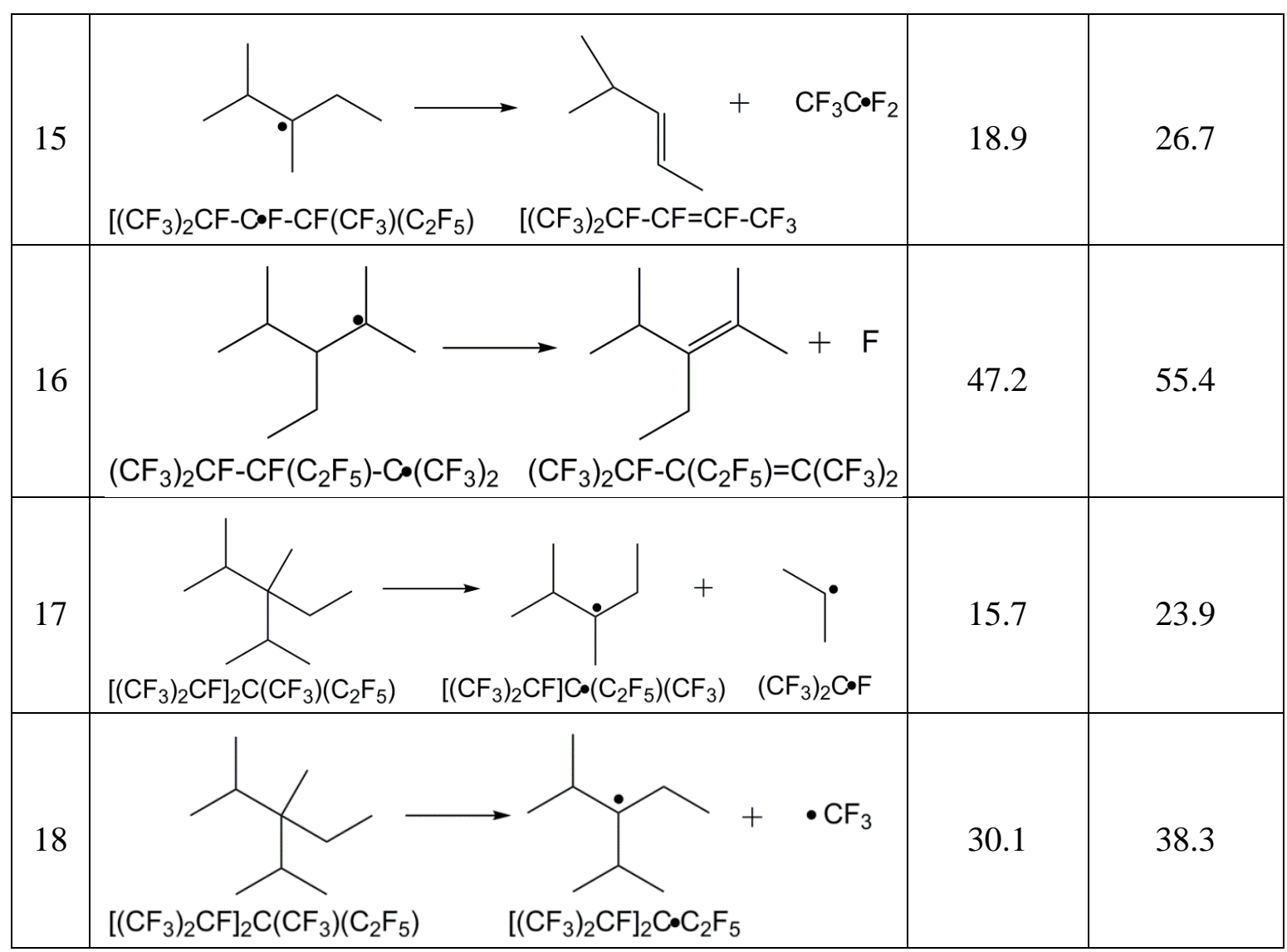

${ }^{\mathrm{a}}$ All missing bonds are to $\mathrm{F}$. Only the $\mathrm{C}$ framework is shown. 


\section{Graphical Abstract}

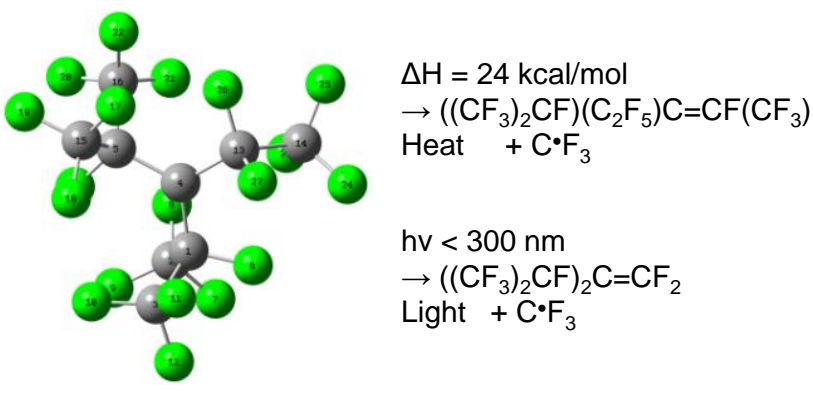


Synopsis: An experimental and computational study of the photodecomposition of the long lived radical $\left[\left(\mathrm{CF}_{3}\right)_{2} \mathrm{CF}\right]_{2} \mathrm{C}^{\bullet} \mathrm{C}_{2} \mathrm{~F}_{5}$ shows that the photodecomposition does not depend on the phase state of the matrix and proceeds by a different mechanism from that for thermal decomposition in terms of the initial bond that is cleaved. 